Article

\title{
Investigating Vapour Cloud Explosion Dynamic Fatality Risk on Offshore Platforms by Using a Grid-Based Framework
}

\author{
Usama Muhammad Niazi ${ }^{1,2}$, Mohammad Shakir Nasif 1,2,*, Masdi Muhammad ${ }^{2}$ \\ and Faisal Khan ${ }^{3}$ (D) \\ 1 Center of Advanced Process Safety (CAPS), Universiti Teknologi PETRONAS, Bandar Seri Iskandar, \\ Perak 32610, Malaysia; ukniaxi@gmail.com \\ 2 Mechanical Engineering Department, Universiti Teknologi PETRONAS, Bandar Seri Iskandar, \\ Perak 32610, Malaysia; masdimuhammad@utp.edu.my \\ 3 Centre for Risk, Integrity and Safety Engineering (C-RISE), Faculty of Engineering \& Applied Science, \\ Memorial University of Newfoundland, St. John's, NL A1B 3X5, Canada; fikhan@mun.ca \\ * Correspondence: mohammad.nasif@utp.edu.my
}

Received: 7 May 2020; Accepted: 3 June 2020; Published: 11 June 2020

\begin{abstract}
The reliability of petroleum offshore platform systems affects human safety and well-being; hence, it should be considered in plant design and operation in order to determine its effect on human fatality risk. Methane Vapour Cloud Explosions (VCE) in offshore platforms are known to be one of the fatal potential accidents that can be attributed to failure in plant safety systems. Traditional Quantitative Risk Analysis (QRA) lacks in providing microlevel risk assessment studies and are unable to update risk with the passage of time. This study proposes a grid-based dynamic risk analysis framework for analysing the effect of VCEs on the risk of human fatality in an offshore platform. Flame Acceleration Simulator (FLACS), which is a Computational Fluid Dynamics (CFD) software, is used to model VCEs, taking into account different wind and leakage conditions. To estimate the dynamic risk, Bayesian Inference (BI) is utilised using Accident Sequence Precursor (ASP) data. The proposed framework offers the advantage of facilitating microlevel risk analysis by utilising a grid-based approach and providing grid-by-grid risk mapping. Increasing the wind speed (from 3 to $7 \mathrm{~m} / \mathrm{s}$ ) resulted in maximum increase of $21 \%$ in risk values. Furthermore, the integration of BI with FLACS in the grid-based framework effectively estimates risk as a function of time and space; the dynamic risk analysis revealed up to $68 \%$ increase in human fatality risk recorded from year one to year five.
\end{abstract}

Keywords: human fatality dynamic risk; Bayesian inference; vapour cloud explosions; CFD modelling; grid-based approach

\section{Introduction}

Offshore oil and gas processing facilities are widely constructed, and their reliable operation is essential to nations' economies and provision of a sustainable supply of fuel. One of the most important aspects of offshore platforms operation is workers' safety. Offshore platforms are equipped with numerous equipment and control systems that have operating procedures and safety measures to operate in order to ensure optimum reliability. Process equipment deviations from normal working conditions, faults in safety system operations, and equipment degradation render offshore facilities vulnerable to failures that may lead to accidents [1,2]. Failures in the processing areas of offshore facilities mainly lead to hydrocarbon release, which can cause fires and explosions [3-5]. The severity 
of damage caused by explosions is high because the congested pipe/equipment configurations on offshore facilities remarkably increase the magnitude of overpressure situations [6].

A number of accidents have occurred in the past that have resulted in human fatalities. The Piper Alpha disaster (1988) resulted in 165 deaths due to explosions caused by the release of hydrocarbons [7]. According to Atherton and Gil [8], a series of explosions occurred on Petrobas P-36 platform (2001) that caused 11 deaths. The BP Deepwater Horizon accident (2010) was caused by a blowout that not only took 11 lives due to explosion, but also caused over $\$ 61$ billion damage [9]. Important lessons were extracted from each fire and explosion accident, and safety designs (such as blast walls, gas leakage detection systems, water deluge and sprinkle systems) and regulations (such as performing detailed Quantitative Risk Analysis (QRA) studies) were improved to prevent future accidents [10]. However, regardless of improvements in safety measures and designs, past accidents indicate that offshore facilities remain susceptible to fire and explosion accidents.

Quantitative Risk Analysis (QRA) is a structured methodology that can be used for overall risk estimation of an offshore facility due to Vapour Cloud Explosion. Conventional QRA estimates the probability of accidents of major hazards, but it has the primary limitation of being static; it cannot capture changes in the estimation of the probability of accidents with time [11]. Recently, QRA methodologies have rapidly progressed in a dynamic direction to address risk issues that are changing due to variation in the operational situation or process environment, such as variations in pressure, geometry, humidity, equipment degradation, or due to experts' beliefs based on mishaps, near misses, and incidents. The methodology also allows for continuous integration with precise information regarding near misses and incidents and updates risk profiles [12,13]. Hence, dynamic risk analysis is essential to ensuring the continuous improvement of safety measures [14]. The four major steps of QRA are hazard identification and ranking, accident probability estimation, consequence analysis and risk evaluation and representation [15].

Conventional QRA cannot update the probability of different accident scenarios [16-18]. This limitation was conceded as one of the major reasons of the Texas refinery accident [19]. Early research on the dynamic probability estimation of accidents adopted the Bayesian Inference (BI) approach. In this approach, Accident Sequence Precursor (ASP) data are employed to update the prior failure probabilities in the system using BI. Meel and Seider [20] were the first to use the concept of ASP data with BI to update the probability of accident scenario estimations for oil and gas processing facilities. They developed a complete dynamic failure assessment methodology, providing an up-to-date scenario of the failure frequency of a process and thereby providing real-time risk profiles.

Kalantarnia et al. [11,19] used the concept of Meel and Seider and developed a methodology using the event tree model and BI to update the probability of different accident scenarios. The methodology was applied to the refinery accident that occurred in Texas City, which showed the capability of dynamic QRA to learn from past accidents and near misses and predict the probability of accident occurrence in subsequent time intervals. Khakzad et al. [21] developed a methodology for dynamic accident probability estimation utilising the bow-tie model by incorporating ASP data, and applied the methodology to a sugar refinery explosion. The failure probability of safety barriers (primary explosion, high concentration alarm, and venting barriers) in the bow-tie model was updated utilising ASP data with BI. The developed methodology was a useful technique in updating the probability of failure of safety barriers, which directly affected the estimated risk.

Abimbola et al. [16] proposed a dynamic safety analysis approach for drilling operations using the bow-tie model and considering an offshore platform. The model was used to represent and estimate the probabilities of possible accident scenarios. Then, real-time data was incorporated using BI to update the probabilities of accident scenarios, and revised risk profiles were presented. Adedigba et al. [22] developed a dynamic risk analysis method that utilises the naïve Bayes algorithm for offshore drilling operations. The dynamic risk profile developed could be helpful in operational decision-making for offshore drilling operations. 
Consequence analysis models major hazards and estimates their consequences in terms of property damage, environmental loss, and human loss. The analysis plays an equally important role in the probability determination of risk estimation. The research mentioned above focuses only on dynamic failure analysis (probability estimation of accident scenarios) and used simplified techniques for modelling significant hazards. Modelling of significant hazards, such as Vapour Cloud Explosions (VCE), is affected by various parameters such as confinements, congestions, wind, and leakage conditions that need to be considered for the accurate estimation of overpressure caused by VCE [23,24]. Based on the analysis of past accidents, the overpressure developed by VCEs is the major reason for human fatality [25].

Computational Fluid Dynamics (CFD) is a technique that can be used for modelling VCE; it considers three-dimensional effects and geometrical obstructions and overcomes the shortcomings of semiempirical modelling [26]. Dadashzadeh et al. [27] developed an integrated risk analysis approach for evaluating human fatality and injury considering the cumulative impact of fire and VCE accident on an offshore facility utilising Flame Acceleration Simulator (FLACS). The authors concluded that human injury and fatality considerably increases if the combined effect of fire and VCE accidents are taken into consideration.

Baalisampang et al. [28] proposed an integrated risk-based framework due to pool fire, VCE, and combustion products, considering human injury and fatality on a processing oil and gas facility. The framework was applied considering accidental release of Liquefied Natural Gas (LNG), development of pooling, and dispersion of methane gas. The authors concluded that the risk due to the cumulative effect of fire, explosion, and combustion-produced toxic gases was more severe and covered a larger area than the individual risk of human fatality and injury. Recently, Zhang et al. [29] determine the human fatality risk due to VCE from a gas tank in storage facility by employing FLACS software. It was concluded that the overpressure results were comparable to the real overpressures developed due to explosions that caused human fatalities. However, past studies have not investigated the effect of wind speed, leak direction, and leak rate on the resulting overpressure and subsequent human fatality risk.

Risk estimation is the last step of QRA, and conventional QRA provides macroscale risk assessment, which gives an overall risk value of target area (entire offshore facility). The grid-based approach facilitates microlevel risk assessment by considering the location and specific details. However, a limited number of research studies have employed the grid-based approach for risk representation [15,30-34]. The grid-based approach has been utilised to analyse explosion and fire risk considering the processing area of an offshore facility [15], establishing design accident loads [30], determining the risk of human fatality from secondary grade release considering a gas dehydration unit [31], risk estimation for processing facilities that are close to residential areas [32], human fatality risk estimation due to VCE accidents on offshore facilities [33], and for risk estimation at hydrogen refueling stations [34].

This research study aims to utilise a grid-based approach for dynamic risk evaluation of human fatalities considering different wind and leakage conditions. Accordingly, the major contribution of this study is the development of the Grid-Based Dynamic Risk Analysis (GDRA) framework, which takes into consideration the transient changes of risk and its effect on human fatalities due to VCE. It includes the changes in the reliability of equipment and instrumentations in any plant with respect to time. This change will affect the probability of failure, hence affecting the risk level. In addition, the developed overpressure due to a VCE varies in different parts of an offshore platform, which is attributed to geometrical effects and weather conditions (such as wind speed), and consequently affect the leaked gas concentration. FLACS CFD software was used to model the VCE.

In past grid-based risk studies, the grid-based approach was utilised for static risk estimation. However, risk tends to change over time. Furthermore, CFD tools were not utilised to simulate VCEs. Such tools consider confinement and congestion on offshore platforms, which strongly affect the overpressures that develop due to a VCE. Moreover, the effect of different wind speeds, leak directions, 
and leak rates on the developed overpressure and subsequent risk of human fatalities have not been investigated.

Considering the limitations of past studies, the development of the GDRA framework will be a useful tool that takes into consideration the dynamic changes in system reliability and failure with respect to time. This framework provides information and guidance to safety engineers and designers to design safe and reliable offshore platforms.

\section{Methodology}

In order to develop the framework to determine the dynamic risk of human fatality due to VCE with varying wind speed, leak rate, and leak direction of methane gas release in offshore platform, a grid-based approach has been employed. Figure 1 presents the steps and techniques used in the current GDRA framework. The framework starts with area calcification to identify hazardous equipment, followed by determining the probability of failure and the updating of the probability with time. To determine the consequence, CFD modelling is used, and the offshore platform was discretised into grids. The modelled CFD results were coupled with the grids to determine the dynamic risk at each grid. Details of each step are presented as follows:

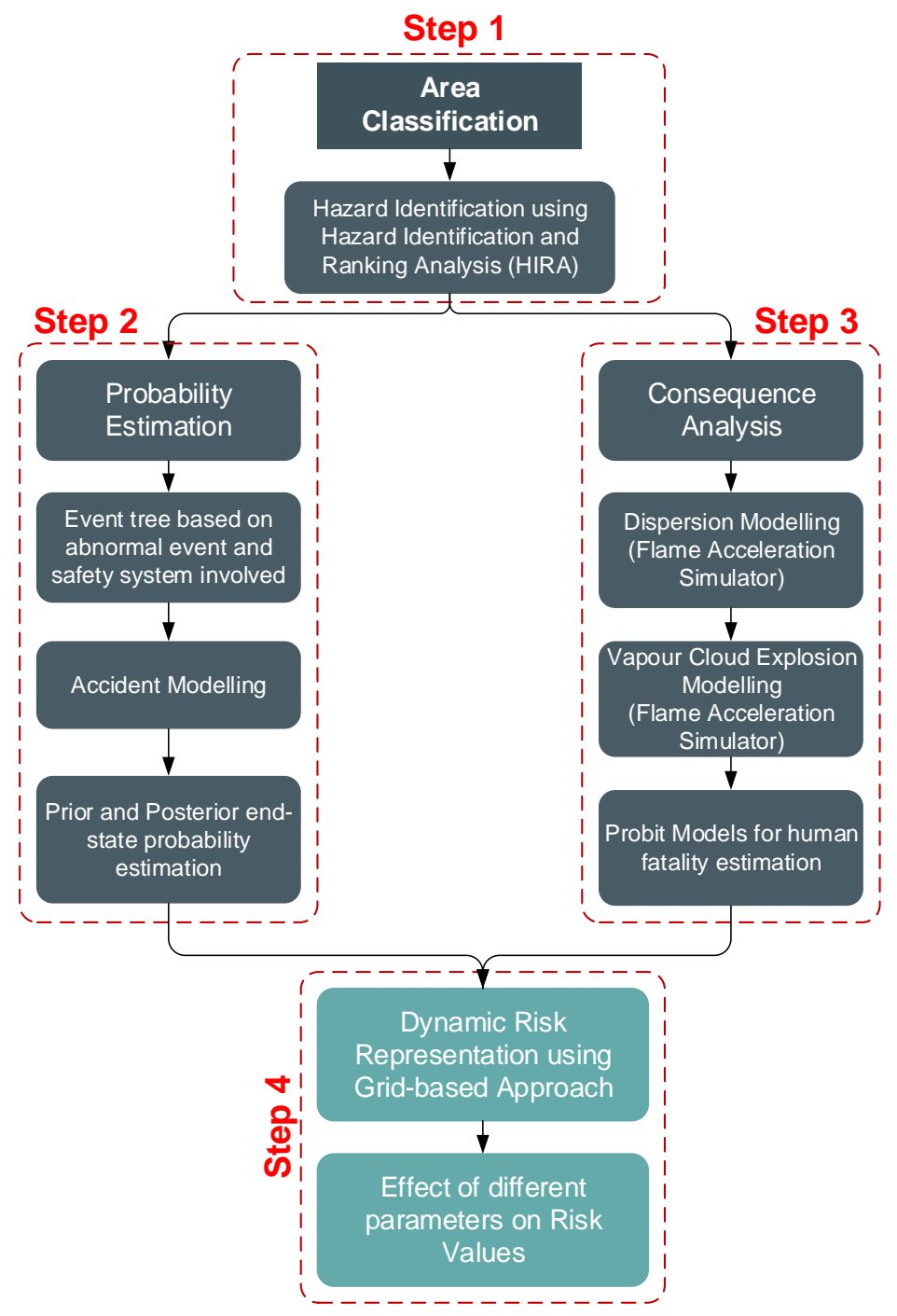

Figure 1. Methodology for Grid-Based Dynamic Risk Analysis (GDRA). 


\subsection{Area Classification and Hazard Identification}

As shown in Figure 1, the first step (step 1) in GDRA is area classification and hazard identification. Identifying critical hazardous areas and equipment is important for detailed and precise risk assessment. A research study by the Health and Safety Executive (HSE) confirmed that accidents that occur in process units account for nearly $80 \%$ of the risk to personnel working on offshore platforms [35]. Therefore, for the current study, the processing deck of an offshore facility is considered.

The next step in GDRA is hazard identification, which is accomplished by using Hazard Identification and Ranking Analysis (HIRA). HIRA provides swift ranking of equipment in terms of damage radii based on physical and chemical energy factors and assigning of different penalties. Energy factors are estimated based on chemical and physical energy by considering heat of combustion of fuel, vapour and processing pressures, and volume of fuel. After estimating this, a net quantitative outcome enables interpretation of the results. The net quantitative score, which represents the equipment damage radius, is evaluated against a ranking system, and each piece of equipment is ranked from extremely hazardous to least hazardous [36]. Table 1 shows the equations employed in HIRA.

Table 1. Hazard Identification and Ranking Analysis (HIRA) formulation. Reproduced with permission from Niazi et al. [33], Process Safety Progress; published by Wiley, 2020.

\begin{tabular}{|c|c|}
\hline \multicolumn{2}{|c|}{ Explosion Index [36] } \\
\hline \multicolumn{2}{|c|}{ Energy factor } \\
\hline Physical energy & $F 2=1.304 \times 10^{-3} \times V \times O P$ \\
\hline Physical energy & $F 3=1.0 \times 10^{-3} \times V /(O T+273)(O P-V P)^{2}$ \\
\hline Chemical energy & $F 1=0.1 \times M \times H c / K$ \\
\hline Formula for final energy estimation & $\begin{array}{c}F=i f\left(p n_{2}=f p_{1}, F 2+F 3, \text { if }\left(p n_{2}=f p_{2}, F_{2}, F_{3}\right)\right) \\
\text { where } f p_{1} \text { and } f p_{2} \text { is a function of } p n_{2}\end{array}$ \\
\hline \multicolumn{2}{|c|}{$\operatorname{Penalties}(p n)$} \\
\hline Temperature & $\begin{array}{l}p n 1=\text { if }(O T>F P<F R P, 1.45, \text { if }(O T>F R P< \\
0.75 \times A I T, 1.75, \text { if }(O T>0.75 \times A I T, 1.95)), 1.1)\end{array}$ \\
\hline Pressure & $\begin{array}{c}p n 2=i f(V P>A P \& P P>V P, p n 2=f p 1 \& F= \\
F 2+F 3 \text { else } F=F 2 \& p n 2=f p 2 \\
\text { if }(A P>V P \& P P>A P, F=F 3 \& p n 2= \\
f p 3 \text { where } f p 1=1+0.6 \times \frac{O P-V P}{O P}, f p 2=1+0.4 \times \\
(O P-V P) / O P), f p 3=1+0.2 \times(O P-V P) / O P)\end{array}$ \\
\hline Capacity & $p n 3=($ Amount of fuel in the given equipment $)$ \\
\hline Chemical characteristics of fuel & $p n 4=M A X(1,0.25 \times(N R+N F))$ \\
\hline Location to nearest hazardous equipment & $\begin{aligned} p n 5= & \text { (penality based on location of equipment in the } \\
& \text { offshore facility layout based on graph) }\end{aligned}$ \\
\hline Equipment Density & $\begin{array}{c}p n 6=(1+\text { percentage area of the equipment in a } \\
30 \mathrm{~m} \text { radius from the equipment/100) }\end{array}$ \\
\hline Damage potential & $D P=(F 1 \times p n 1+F \times p n 2) \times p n 3 \times p n 4 \times p n 5 \times p n 6)$ \\
\hline Damage Radii & $\mathrm{FEDI}=4.76 \times D P^{0.33}$ \\
\hline
\end{tabular}

\subsection{Accident Probability Calculation}

After ranking the equipment systems by employing the HIRA methodology, the equipment with the highest damage radius is selected and the probability of an unwanted event is estimated (step 2 in Figure 1). In equipment, many different unwanted events may occur due to the failure of safety systems considering the initial abnormal event. Some different initial abnormal events may occur according to deviations in fluid flow, pressure, and temperature [37].

In this research, the high flow entering a piece of equipment is considered to be the initial abnormal event as this condition is a highly likely abnormal event [38]. Three possible events (consequences) that may occur due to high flow entering the equipment are high-pressure release, process shutdown, and safe operation; these events are named "end-states". Amongst the possible consequences based 
on high flow, high-pressure release forms a flammable vapour cloud, which, on ignition, may result in a VCE accident. In order to link the initial abnormal event to its end-states and to calculate the probabilities of different consequences, an event tree is employed.

\subsubsection{Accident Modelling}

The accident is modelled as a chain of events in an event tree through an inductive logic approach. The event tree model represents different possible end-states as the outcome of an abnormal event [39]. The event tree model of equipment is developed based on the defined initial abnormal event, which is high flow entering the equipment, and different end-states considering success and failure of safety systems.

In order to calculate the failure probability of the different safety systems attached to a piece of equipment, the probability of each safety system is estimated using the probability distribution function as it expresses the failure probability of safety systems more accurately [18]. The selection of beta distribution is decided due to its discreetness and time dependency. Furthermore, beta distribution with binomial distribution develops a conjugate pair that can be employed with BI to update the failure probabilities of the safety system for dynamic risk estimation [11]. In addition, most past studies related to dynamic risk analysis have used beta distribution for updating the probabilities of different accidents with respect to time [11,17-20]. Therefore, in the current study, beta distribution is employed.

Beta distribution has two parameters: alpha $(\alpha)$ and beta $(\beta)$, which are estimated by considering the failure mean and variance of each safety system. The mean and variance of failure of each safety system is taken from the Offshore Reliability Data handbook (OREDA) which is considered as valid and acceptable data by researchers and industries, and is widely used to estimate the probability of failure of different safety systems [40]. Given that a single value of the probability of failure of the safety system is used to calculate probability of different end-states, the mean value of the beta distribution is taken as the failure probability.

\subsubsection{Prior and Posterior End-State Probabilities}

After calculating the safety system probabilities, the probabilities of different end-states are estimated by employing the event tree method. These estimated probabilities are termed prior end-state probabilities $P_{j}$ and represent probabilities of different end-states at the design stage. With the passage of operating time of equipment, near misses and incidents (ASP data) are recorded. In order to obtain ASP data, one preferred method is to obtain from experts who have number of years of experience in conducting QRA $[17,18,20]$. For the current study, ASP data was taken from four safety field experts who have more than 10 years of experience in offshore facilities. The ASP data are incorporated to update $P_{j}$ by utilising BI; the updated $P_{j}$ is the posterior end-state probabilities $P_{j, t}$.

$\mathrm{BI}$ is a probabilistic method that utilises the principle of conditional probability to acquire an updated distribution (posterior distribution) based on the initial distribution (prior distribution) [41]. This approach relates the prior probability distribution to the posterior probability distribution by a likelihood function. Let $x_{i}$ represent the failure probability of the safety system, $p\left(x_{i}\right)$ represents the initial probability (prior probability distribution function), and $g\left(A S P / x_{i}\right)$ represents the likelihood function. By relating the prior probability distribution with the likelihood function, $p\left(x_{i} / A S P\right)$ is obtained, which represents the posterior probability distribution function. The equation is derived as follows [41]:

$$
p\left(x_{i} / A S P\right) \propto g\left(A S P / x_{i}\right) \times p\left(x_{i}\right)
$$

ASP data are obtained by consulting the expert and are used to form the likelihood function $g\left(A S P / x_{i}\right)$ by employing a binomial distribution function [11]. Afterwards, the posterior probability distribution is calculated as follows:

$$
p\left(x_{i}\right) \propto x_{i}^{\alpha-1} \times\left(1-x_{i}\right)^{\beta-1}
$$




$$
\begin{gathered}
g\left(A S P / x_{i}\right) \propto x_{i}^{f}\left(1-x_{i}\right)^{s} \\
p\left(x_{i} / A S P\right) \propto x_{i}^{\alpha-1}\left(1-x_{i}\right)^{\beta-1} \times x_{i}^{f}\left(1-x_{i}\right)^{s} \propto x_{i}^{\alpha+f-1}\left(1-x_{i}\right)^{\beta+s-1}
\end{gathered}
$$

Hence, a beta-binomial posterior distribution is obtained with new parameters $\alpha+f$ and $\beta+s$, where $s$ and $f$ represent the success and failure of each safety system, respectively, and are obtained by utilising ASP data. The prior failure probability of each safety system is obtained by considering the mean value $(\mu)$ of the beta distribution as follows [38]:

$$
\mu_{p r}=\frac{\alpha}{\alpha+\beta}
$$

where $\mu_{p r}$ represent the prior failure probability of safety system. ASP data are used to estimate the posterior failure probability as follows [38]:

$$
\mu_{p s}=\frac{\alpha+f}{\alpha+f+\beta+s}
$$

where $\mu_{p s}$ represents the posterior failure probability of a safety system. In order to estimate the $\alpha$ and $\beta$ parameters, mean $(\mu)$ and variance $(\sigma)$ are utilised. The variance of the distribution is presented as follows [41]:

$$
\text { Variance }=\sigma=\frac{\alpha \beta}{(\alpha+\beta)^{2} \times(\alpha+\beta+1)}
$$

Hence, in this way, beta-binomial distribution updates the probability of all safety systems by utilising ASP data that presents updated information and helps to estimate the posterior probabilities of safety systems and, consequently, probabilities of different end-states. The use of beta binomial distribution for updating the probabilities of failures has been previously employed by number of studies [11,17-20], which shows that the method is well verified for use in updating the failure probabilities of different safety systems.

\subsection{Consequence Analysis}

The third step in QRA (step 3 in Figure 1) is consequence analysis, which helps in modelling and estimating the impact of VCEs. Based on even tree analysis, a high-pressure release (considering methane gas) needs to be modelled, followed by dispersion and delayed ignition. FLACS is a specialised CFD software that models dispersion and explosion as a 3D model and has been widely used and validated by numerous studies [23,42-48]. In this research study, FLACS was employed to model the release of methane gas, its dispersion, and the resulting VCE. This tool solves equations of momentum, mass, and enthalpy by using the finite volume method. FLACS also uses mixture fraction solved along with a combustion model. Meanwhile, turbulence is modelled utilising the Reynold-Averaged Navier-Stokes (RANS) approach.

\section{Quantification of the Probability of Human Fatalities}

The peak overpressure and the impulse resulting from a VCE is considered for causing human fatalities [49]. Three major impacts that result in fatality are head impact, lung damage, and whole-body displacement. To calculate the probability of fatality due to each impact $k$, probit models correlating the overpressure developed by VCE to human fatality are employed to evaluate the probability of each impact [50].

The following equation is utilised to estimate the probability $P_{k}$ of fatality due to head impact, lung damage, and whole-body displacement [50]:

$$
P_{k}=\frac{1}{2}\left[1+\operatorname{erf}\left(\frac{P_{r}-5}{\sqrt{2}}\right)\right]
$$


where $\operatorname{erf}$ is the error function and $P_{r}$ is the probit function, which is estimated as follows [50]:

$$
P_{r}=c 1+c 2 \ln S
$$

where variable $S$ is specified based on different effects $k$ with coefficients $c 1$ and $c 2$, as listed in Table 2 .

Table 2. $S$ and $P_{r}$ functions with coefficients for all effects $(k)$.

\begin{tabular}{ccc}
\hline Effect $(\boldsymbol{k})$ & $P_{r}$ & $S$ \\
\hline Head Impact & $5.0-8.49 \times \ln S$ & $\frac{2.43 \times 10^{3}}{P_{s}}+\frac{4 \times 10^{8}}{P_{s} i_{s}}$ \\
Whole-body displacement & $5.0-2.44 \times \ln S$ & $\frac{7.38 \times 10^{3}}{P_{s}}+\frac{1.3 \times 10^{9}}{P_{s} i_{s}}$ \\
Lung damage & $5.0-5.74 \times \ln S$ & $\frac{4.2}{P_{s}+\frac{5 P_{s}^{2}}{P_{s}+14 \times 10^{5}}}+\frac{P_{s} \times 14 \times 10^{5}}{P_{s}+7 \times 10^{5}}$ \\
\hline
\end{tabular}

Where $i_{s}$ impulse (pa.s) and $P_{s}$ is peak overpressure (pa).

\subsection{Dynamic Risk Estimation Using a Grid-Based Approach}

As the probability of having a VCE accident is continuously updated using ASP data, a dynamic risk of human fatality for each effect $k$ was estimated at each year considering different wind speeds, leak rates, and leak directions (step 4 in Figure 1) using the following equation:

$$
\operatorname{Risk}_{i, j, k, t}=P_{j, t} \times C_{i, k}
$$

where Ris $_{i, j, k, t}$ is the human fatality risk at year $t$ considering various effects $k$ at a particular location $i$ for an accident scenario $j ; P_{j, t}$ is posterior probability of end-state (accident scenario $j$ ) at year $t ; C_{i, k}$ is the probability of human fatality due to a given effect $k$ at location $i$. Onboard personnel are considered present at each location on the offshore platform for the entire period.

\section{Model Development}

The developed GDRA methodology to estimate the dynamic fatality risk due to VCE is applied to the processing deck of an offshore platform. The processing deck on an offshore platform consists of numerous equipment types for processing and transporting hydrocarbons, such as separators, pumps, compressors, and scrubbers.

Figure 2 represents the processing deck of an offshore platform that consists of different modules (M1 to M6) with different equipment installed in each module and the 3D model developed in the Computer Aided Scenario Design (CASD) of FLACS.

In this framework, VCE modelling is performed considering different input parameters (leak rates, leak directions, and wind speeds). In order to model the high pressure methane gas release, the direction of leak and flow rate should be included in the modelled cases. Norsk Sokkels Konkurranseposisjon (NORSOK) standard [51] provided the required modelling conditions to be considered in each case, which include leak direction and leak rate range. The modelled wind speed were selected from South China Sea meteorological data in West Malaysia [52]. Table 3 lists the range of wind speed, leak direction, and leak rate according to the NORSOK standard and meteorological data.

To model methane gas leak duration, according to the Det Norske Veritas (DNV) guidelines, the installed safety instrument systems is expected to detect and isolate the release in approximately $1.5 \mathrm{~min}$ [53]. As a conservative approach, the modelled leak duration was $2 \mathrm{~min}$.

A total of 60 dispersion and 60 VCE CFD simulations were analysed based on the parameters listed in Table 3.

The parameters mentioned in Table 3 have been included in the FLACS model, and the dispersion of high pressure release of methane gas was modelled. Based on the FLACS guidelines, the dispersion and VCE modelled domains should be twice the size of offshore facility to reduce the boundary effects on the simulation results [54]. 
After carrying out the dispersion simulations at different wind speeds, leak rates, and leak directions, boundary conditions were defined for VCE simulation and overpressure was measured.

To estimate the dynamic risk of human fatality due to VCE, a grid-based approach was adopted. The complete processing deck of the offshore facility with dimensions of $82 \times 34 \mathrm{~m}$ in the $\mathrm{x}$ - and $\mathrm{y}$-axes was split into a total of 697 grids, as seen in Figure 3.

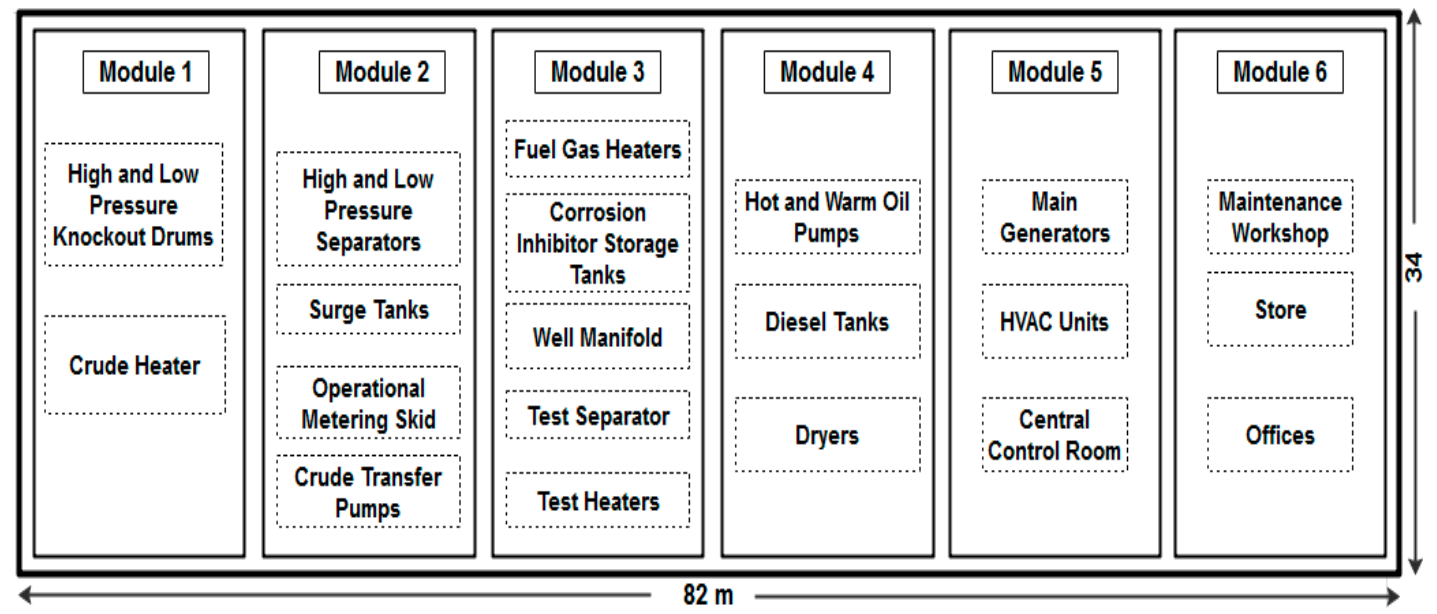

(a) Equipment in different modules of the processing deck.

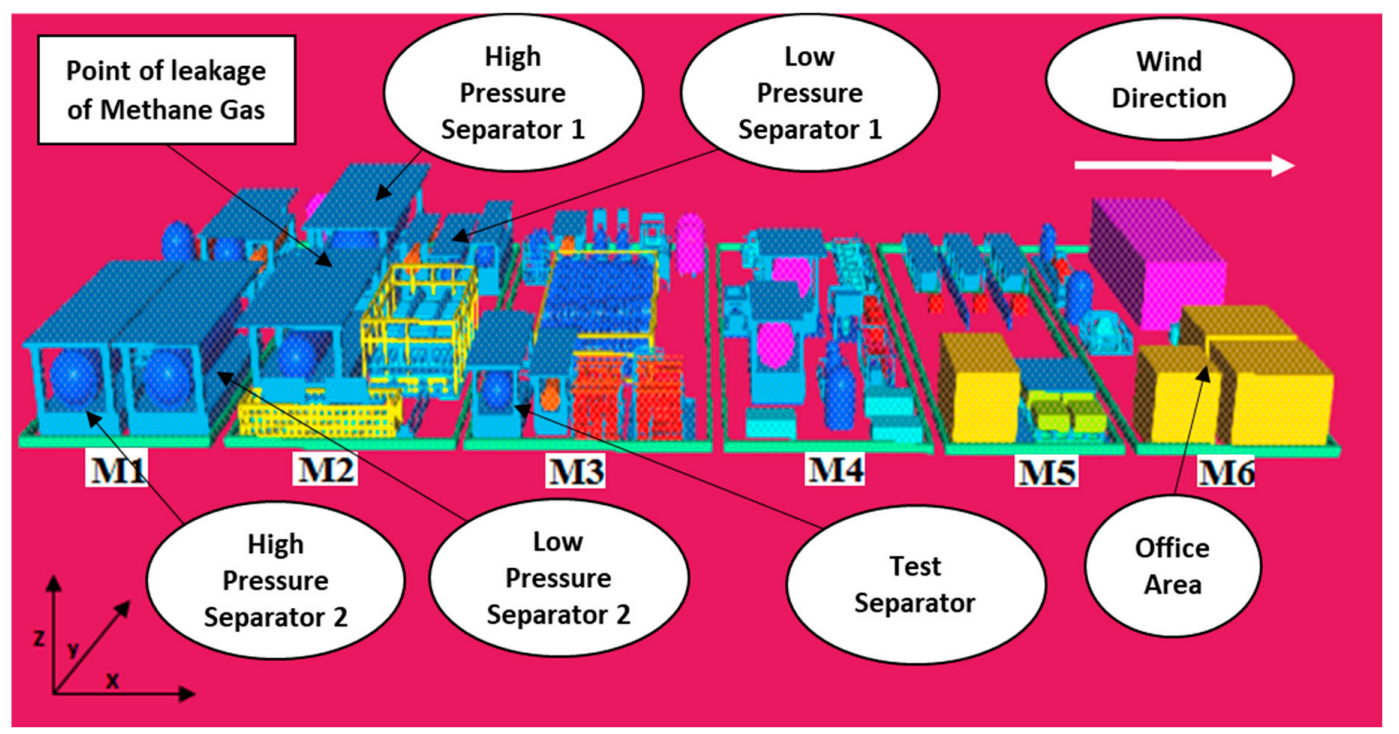

(b) Entire processing deck geometry (Flame Acceleration Simulator (FLACS) model).

Figure 2. Processing deck of an offshore facility. Reproduced with permission from Niazi et al. [33], Process Safety Progress; published by Wiley, 2020.

Table 3. Parameters and states considered.

\begin{tabular}{cc}
\hline Parameters & States \\
\hline Wind Speed & $3,5,7(\mathrm{~m} / \mathrm{s})$ \\
Leak Direction ${ }^{1}$ & $\mathrm{RZ}-, \mathrm{RZ}+, \mathrm{RX}+, \mathrm{RY}+, \mathrm{RY}-($ axis shown in Figure 2$)$ \\
Leak Rate & $16,31,46,61(\mathrm{~kg} / \mathrm{s})$ \\
Leak Duration & 2 min
\end{tabular}

${ }^{1}$ where $\mathrm{RZ}$ - is leak direction in negative $\mathrm{z}$-axis, $\mathrm{RZ}+$ is leak direction in positive $\mathrm{z}$-axis, $\mathrm{RX}+$ is leak direction in positive $\mathrm{x}$-axis, $\mathrm{RY}+$ is leak direction in positive $\mathrm{y}$-axis and $\mathrm{RY}$ - is leak direction in negative $\mathrm{y}$-axis. 


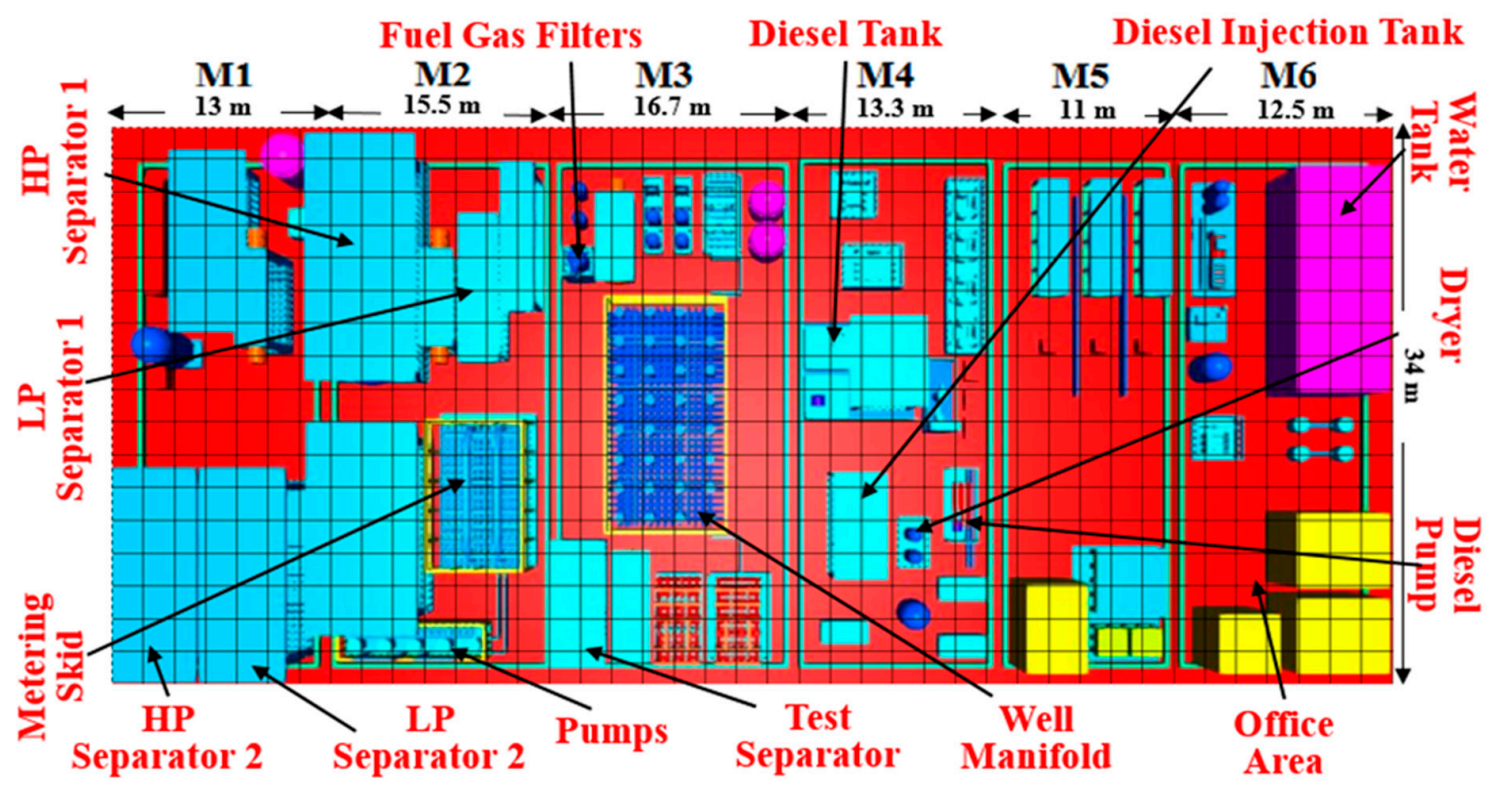

Figure 3. Grid-based approach. Reproduced with permission from Niazi et al. [33], Process Safety Progress; published by Wiley, 2020.

By placing a monitor point at each grid, overpressure produced by VCE was evaluated and the corresponding human fatality risk was calculated at each grid for five years. The acceptable fatality risk limit for any offshore facility is $1 \times 10^{-4}$, and a risk value higher than this is considered unacceptable [55].

In order to analyse the effect of different parameters (wind and leakage conditions) on fatality risk (lung damage, whole-body displacement, and head impact), unacceptable risk area was calculated for each simulation case and expressed in terms of percentage.

\section{Results and Discussions}

This section presents the results of the GDRA of human fatality obtained from implementing the methodology presented in Section 2.

\subsection{Equipment Hazard Identification}

Separators are identified as important processing equipment operating on offshore facility. For the modelled offshore facility, a total of five different separators are installed, e.g., Low-Pressure (LP) Separators, High-Pressure (HP) Separators, and a Test Separator. Therefore, the damage radius of each separator was estimated, and different separators were ranked. Table 4 lists the operating conditions of the different separators used as input in HIRA, and the energy factors and different penalties were calculated.

It can be seen from Table 4 that HP separator 1 recorded the maximum damage radius of 388 $\mathrm{m}$, while the Test separator recorded the smallest radius, with $111 \mathrm{~m}$. The primary reason for HP separator 1 having the largest damage radius is due to its handling of large quantities of hydrocarbon and operating at high pressure. Since HP separator 1 recorded the maximum damage radius, it will be considered in failure probability and risk investigations. 
Table 4. Hazard identification of separators using HIRA.

\begin{tabular}{|c|c|c|c|c|c|c|c|c|c|c|c|}
\hline \multirow{2}{*}{ 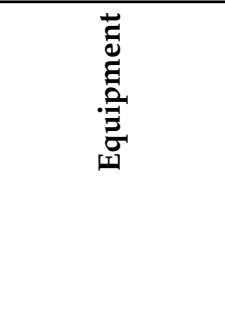 } & \multirow{2}{*}{ 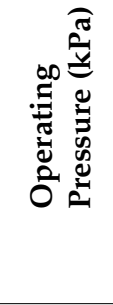 } & \multirow{2}{*}{ 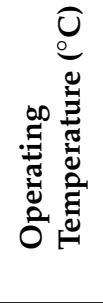 } & \multirow{2}{*}{ 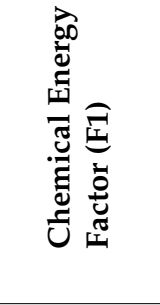 } & \multicolumn{2}{|c|}{ Physical Energy Factor } & \multirow{2}{*}{ 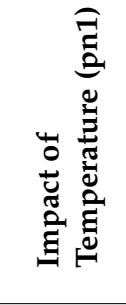 } & \multirow{2}{*}{ 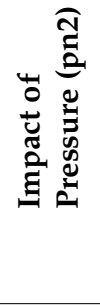 } & \multirow{2}{*}{ 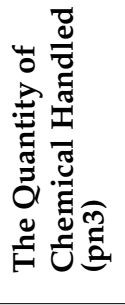 } & \multirow{2}{*}{ 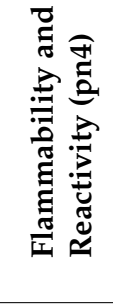 } & \multirow{2}{*}{ 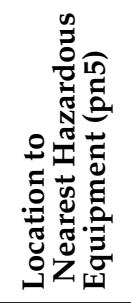 } & \multirow{2}{*}{ 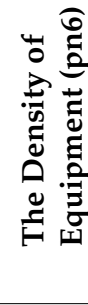 } \\
\hline & & & & $F 2$ & $F 3$ & & & & & & \\
\hline HP Separator 1 & 1724 & 54 & $1.19 \times 10^{5}$ & 490 & $7 \times 10^{-13}$ & 1.45 & 1.04 & 1.8 & 1 & 1.95 & 1.025 \\
\hline HP Separator 2 & 350 & 54 & $3.51 \times 10^{4}$ & 29.45 & $3 \times 10^{-14}$ & 1.45 & 1 & 1.2 & 1 & 1.95 & 1.009 \\
\hline LP Separator 1 & 345 & 66 & $4.43 \times 10^{4}$ & 36.67 & $2 \times 10^{-14}$ & 1.6 & 1 & 1.3 & 1 & 1.95 & 1.012 \\
\hline LP Separator 2 & 345 & 66 & $1.68 \times 10^{4}$ & 13.9 & $5 \times 10^{-14}$ & 1.6 & 1 & 1.15 & 1 & 1.95 & 1.004 \\
\hline Test Separator & 1479 & 71 & $9.1 \times 10^{5}$ & 16.43 & $5 \times 10^{-12}$ & 1.6 & 1 & 1 & 1 & 1.9 & 1.003 \\
\hline \multicolumn{12}{|c|}{ (DP and FEDI) } \\
\hline & & & & \multicolumn{5}{|c|}{ Damage Potential (DP) } & \multicolumn{3}{|c|}{ FEDI (Damage Radius) (m) } \\
\hline & \multicolumn{3}{|c|}{ HP Separator 1} & \multicolumn{5}{|c|}{$6.21 \times 10^{5}$} & \multicolumn{3}{|c|}{388} \\
\hline & \multicolumn{3}{|c|}{ HP Separator 2} & \multicolumn{5}{|c|}{$1.20 \times 10^{5}$} & \multicolumn{3}{|c|}{226} \\
\hline & \multicolumn{3}{|c|}{ LP Separator 1} & \multicolumn{5}{|c|}{$1.82 \times 10^{5}$} & \multicolumn{3}{|c|}{259} \\
\hline & \multicolumn{3}{|c|}{ LP Separator 2} & \multicolumn{5}{|c|}{$6.06 \times 10^{4}$} & \multicolumn{3}{|c|}{180} \\
\hline & \multicolumn{3}{|c|}{ Test Separator } & \multicolumn{4}{|c|}{$4.64 \times 10^{3}$} & & \multicolumn{3}{|c|}{111} \\
\hline
\end{tabular}




\subsection{Accident Modelling}

After identifying the most hazardous equipment, event tree analysis is utilised for determining the probabilities of end-states (consequences), and later, BI is used for updating the probabilities of the different end-states of the accident model.

\subsubsection{Process Description and Safety System}

As separators operate continuously, the probability of high flow (an abnormal event) entering the separators through the input pipes is quite significant. Some safety systems are installed to control such abnormal events. Amongst the different end-states that might occur due to safety system failures, high-pressure release will form a vapour cloud, and delayed ignition may cause VCE.

To maintain the pressure of hydrocarbon gas in HP separator 1, safety systems such as High-Pressure Alarm (HPA), Pressure Safety Valve (PSV), and basic process control for pressure, which consist of Pressure Control Valve (PCV), Pressure Indicator Controller (PIC), and Pressure Transmitter (PT), are utilised. To control the liquid (crude oil) level, High-Level Alarms (HLA) and basic process control for handling level such as Level Control Valve (LCV), Level Indicator Controller (LIC), and Level Transmitter (LT) are used. If these safety systems fail to operate, a shutoff valve, normally termed an Emergency Shutdown Valve (ESD), is fitted in the system, which will cut the supply of gas and oil, resulting in complete shutdown.

In case of high flow entering the system, the pressure-handling loop, which consists of PT, PIC, and PCV, will be activated, and the excessive flow of natural gas will flow through the PCV. If the pressure-handling loop does not activate, PSV will release the excess vapour to reduce the pressure in the system. HPA will be triggered in the case of PSV malfunction, and the system will shut down.

Similarly, the level-handling loop will operate the LT, LIC, and LCV to control the level in the system. HLA will be triggered in case the level-handling loop fails to activate. As the last safety barrier, ESD will be triggered to completely shut down the entire system. However, if the ESD fails to activate, high-pressure release or rupture of oil and gas will occur and may result in a VCE scenario.

An accident model is developed using the event tree to relate an unusual initial event to a potential accidental event. High flow rate is assumed as an abnormal event in HP separator 1, wherein three consequences (end-states) may occur due to failure of safety systems. These three consequence are: safe operation (A), emergency shutdown (B) and high pressure release (C).

Figure 4 shows the event tree analysis of HP separator 1, which relates the high flow to the different end-states. $x_{i}$ represents the probability of failure of the safety systems, which is calculated utilising the parameters of the beta distribution.

Table 5 lists the parameters $(\alpha$ and $\beta$ ) of the beta distribution for different safety systems attached to HP separator 1.

Table 5. Beta distribution parameters for different safety systems.

\begin{tabular}{ccc}
\hline Safety System & Alpha $(\alpha)$ & Beta $(\beta)$ \\
\hline PT & 10 & 490 \\
PIC & 10 & 490 \\
PCV & 0.6 & 17 \\
PSV & 0.4 & 8 \\
HPA & 9 & 51 \\
LT & 3.4 & 54 \\
LIC & 11 & 539 \\
LCV & 4.6 & 138 \\
HLA & 9 & 51 \\
ESD & 0.25 & 2.5 \\
\hline
\end{tabular}




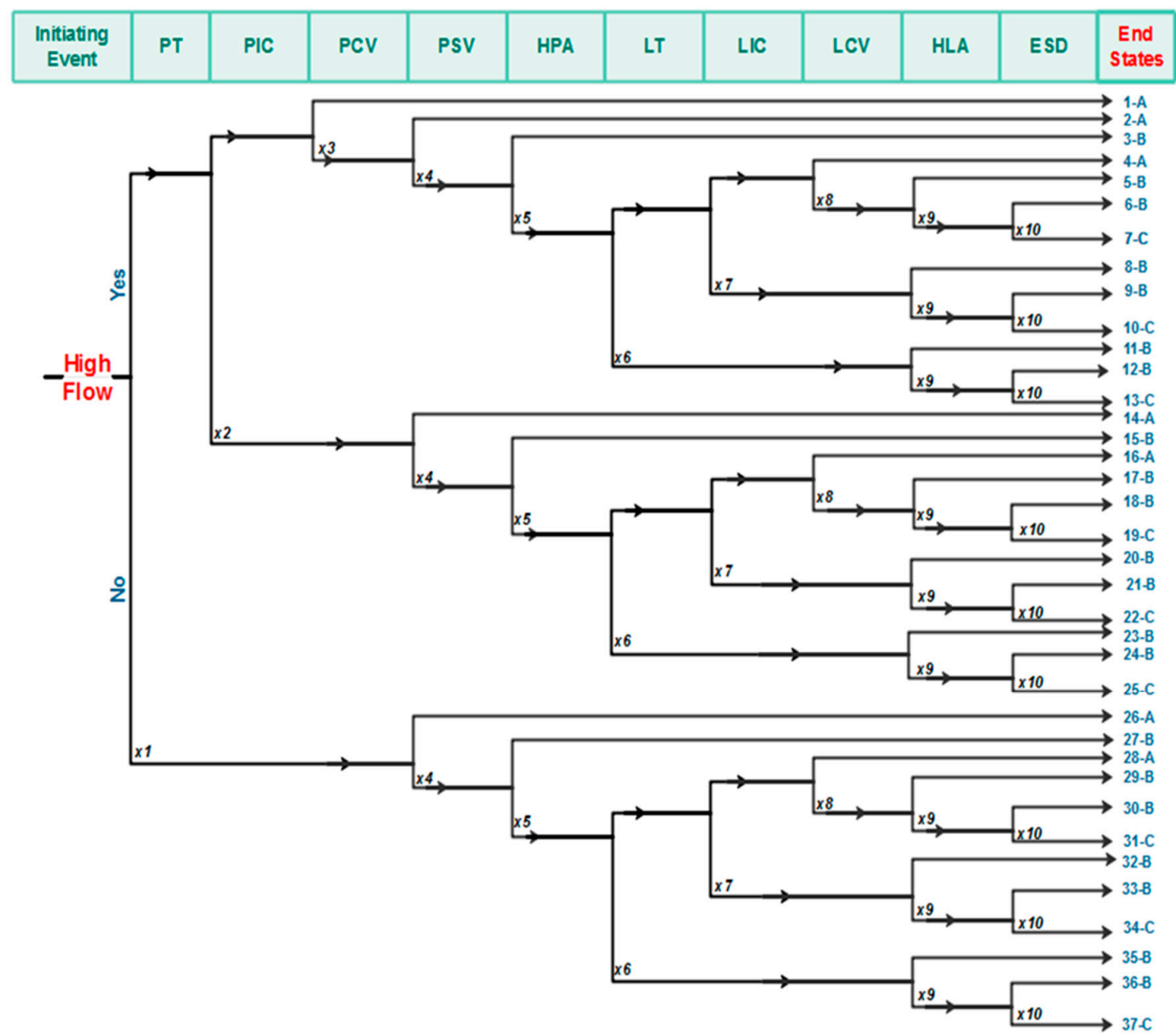

Figure 4. High-pressure (HP) separator 1 event tree model. Reproduced with permission from Niazi et al. [33], Process Safety Progress; published by Wiley, 2020.

ASP data in the last five years of operation of HP separator 1 were obtained from experts and incorporated by using BI to obtain posterior probabilities $\left(P_{j, t}\right)$ at different years. ASP data on HP separator 1 record the number of times the end-states (mentioned in Figure 4) occurred over five years concerning the failure of a particular safety system. It is worth mentioning that in this research, data were recorded from four experts, all of whom have more than 10 years of experience. It was found that when the recorded data of each expert were incorporated in the framework, the variation in the risk results values were around $2 \%$.

This means that the effect of variation in expert opinion on the results was marginal. Hence, in this research, and to be conservative, the expert who provided the highest cumulative ASP data was selected and presented in Table 6.

\subsubsection{Probability Updating of End-States of Accident Model}

Before utilising the BI method by employing beta binomial distribution, the method was verified against the practical case of a pressurised water reactor, and the results were in good agreement with the published research [56,57]. For details, readers may refer to [57].

By utilising BI with beta-binomial distribution, $P_{j, t}$ is estimated for safe operation (a), process shutdown (b), and high-pressure release/rupture (c). In order to investigate the effect of ASP data on the resulting $P_{j, t}$, Figure 5 graphically presents the trend of $P_{j, t}$ for (a), (b), and (c) from 0 to 5 years. 
Table 6. Cumulative Accident Sequence Precursor (ASP) data for HP separator 1 for the last five years.

\begin{tabular}{|c|c|c|c|c|c|}
\hline End-State in Figure 4 & Year 1 & Year 2 & Year 3 & Year 4 & Year 5 \\
\hline $1-\mathrm{A}$ & 3 & 4 & 6 & 8 & 9 \\
\hline $2-\mathrm{A}$ & 1 & 1 & 2 & 3 & 4 \\
\hline $3-B$ & 0 & 1 & 4 & 5 & 6 \\
\hline $4-\mathrm{A}$ & 0 & 1 & 4 & 5 & 7 \\
\hline $5-\mathrm{B}$ & 1 & 2 & 4 & 5 & 7 \\
\hline $6-B$ & 0 & 1 & 3 & 3 & 4 \\
\hline $7-\mathrm{C}$ & 0 & 1 & 1 & 1 & 2 \\
\hline $8-B$ & 0 & 0 & 2 & 3 & 5 \\
\hline 9-B & 1 & 2 & 3 & 4 & 5 \\
\hline $10-C$ & 1 & 1 & 1 & 2 & 3 \\
\hline $11-\mathrm{B}$ & 1 & 1 & 1 & 2 & 2 \\
\hline $12-B$ & 0 & 1 & 2 & 3 & 3 \\
\hline $13-\mathrm{C}$ & 0 & 0 & 0 & 1 & 1 \\
\hline $14-\mathrm{A}$ & 1 & 2 & 4 & 6 & 7 \\
\hline $15-B$ & 1 & 2 & 4 & 4 & 6 \\
\hline $16-\mathrm{A}$ & 0 & 0 & 2 & 2 & 3 \\
\hline $17-B$ & 1 & 1 & 1 & 2 & 3 \\
\hline 18-B & 1 & 3 & 4 & 4 & 6 \\
\hline 19-C & 1 & 1 & 2 & 2 & 3 \\
\hline $20-B$ & 1 & 1 & 1 & 2 & 4 \\
\hline 21-B & 0 & 1 & 1 & 2 & 4 \\
\hline $22-C$ & 0 & 1 & 1 & 1 & 2 \\
\hline $23-B$ & 0 & 1 & 3 & 3 & 4 \\
\hline $24-B$ & 0 & 1 & 3 & 3 & 4 \\
\hline $25-C$ & 0 & 1 & 2 & 2 & 2 \\
\hline $26-\mathrm{A}$ & 1 & 2 & 4 & 5 & 6 \\
\hline $27-B$ & 1 & 1 & 2 & 3 & 5 \\
\hline $28-\mathrm{A}$ & 0 & 0 & 1 & 4 & 5 \\
\hline $29-B$ & 1 & 2 & 2 & 2 & 2 \\
\hline $30-B$ & 0 & 0 & 0 & 2 & 2 \\
\hline $31-C$ & 1 & 1 & 1 & 2 & 2 \\
\hline $32-B$ & 0 & 0 & 0 & 1 & 3 \\
\hline $33-B$ & 1 & 2 & 2 & 2 & 3 \\
\hline $34-C$ & 0 & 0 & 0 & 0 & 1 \\
\hline $35-B$ & 1 & 2 & 2 & 2 & 3 \\
\hline $36-B$ & 0 & 1 & 1 & 3 & 4 \\
\hline $37-C$ & 0 & 1 & 1 & 1 & 0 \\
\hline
\end{tabular}

Figure 5 shows that the probability of (a) at year 0 (design stage) is estimated to be $9.97 \times 10^{-1}$; the probability of $(b)$ is $3.0 \times 10^{-3}$, and that of $(c)$ is $7.8 \times 10^{-7}$. At the design stage (year 0 ), the separator begins functioning; therefore, the failure probabilities of the safety systems do not include the ASP data that results in a high probability of (a) and low probability of (b) and (c). However, over time, near misses and incidents (ASP) are observed, as presented in Table 5. By incorporating the ASP data utilising BI, it can be seen that $P_{j, t}$ changes drastically. At year 5 , the probability of (a) decreases to $6.3 \times 10^{-1}$, as shown in Figure 5a. However, the probabilities of (b) and (c) increase to $3.4 \times 10^{-1}$ and $1.9 \times 10^{-2}$, respectively, at year 5 , as shown in Figure $5 b, c$, respectively. The results clearly show the influence of ASP data on the resulting probabilities of the different end-states. Furthermore, an increase in the probability of (c) increases the probability of natural gas release resulting in VCE. 


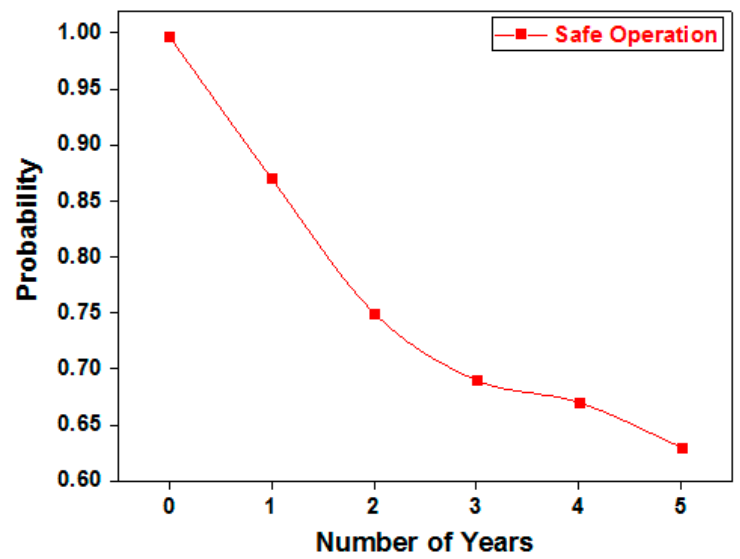

(a)

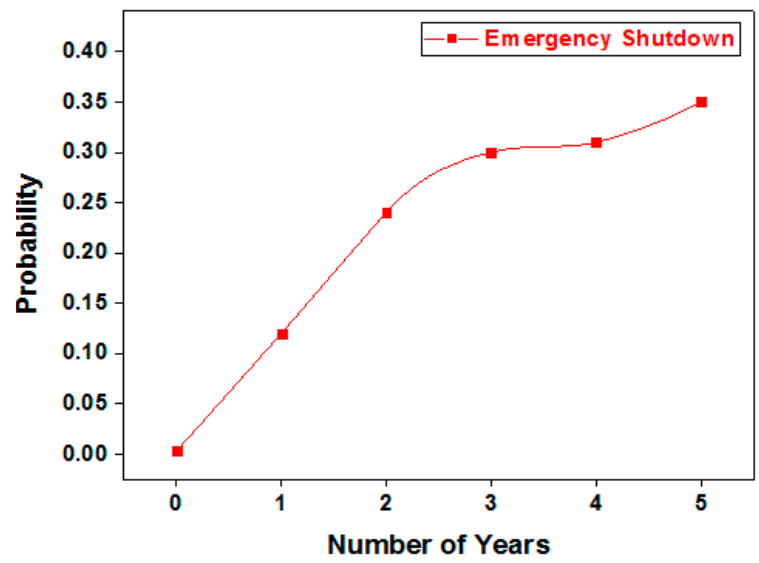

(b)

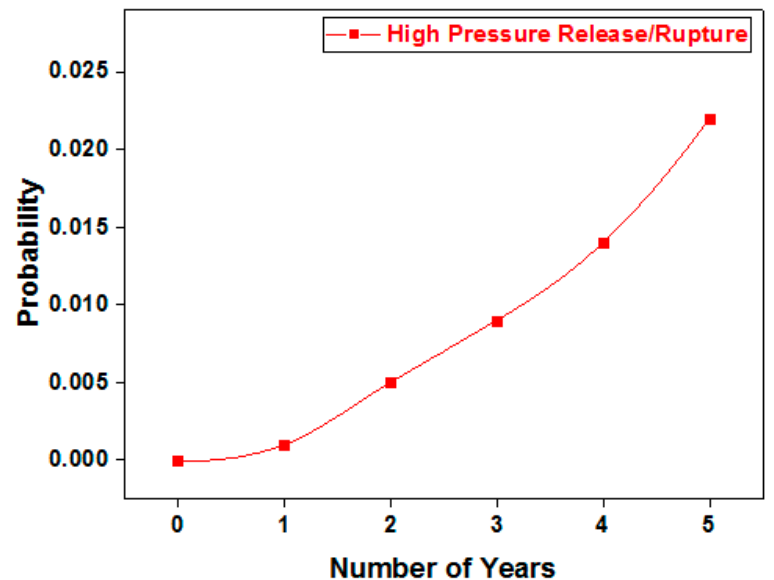

(c)

Figure 5. Updated probabilities of different end-states $P_{j, t}$ from year 0 to 5 . (a) Safe operation. (b) Process shutdown. (c) High-pressure release/rupture.

\subsection{Consequence Analysis}

As mentioned, FLACS is a well-validated CFD software for modelling dispersion and VCE simulations [23,42-45]. In this study, FLACS was used to predict the overpressure produced by VCE considering different leakage and wind speed conditions on the processing deck of an offshore facility that was made in CASD (pre-processor) of FLACS, as shown in Figure $2 b$. The dimensions of the processing deck of the offshore facility are $82 \mathrm{~m} \times 34 \mathrm{~m} \times 7 \mathrm{~m}$. Before carrying out VCE simulation, VCE modelling has been validated against the explosion test performed by Bae et al. [44]. The difference 
between the modelling results and experimental measurement was less than $10 \%$ which is considered as in good agreement. For details, readers may refer to Niazi [57].

\subsubsection{Mesh Sensitivity Study}

Grid size was varied progressively to determine the optimum mesh size. To simulate the VCE utilising FLACS, the modelling process is performed in two separate steps. In the first step, dispersion of methane gas modelling resulting in flammable vapour cloud is modelled. The second step is modelling of the ignited flammable vapour cloud, which causes VCE. Hence, separate mesh sensitivity studies for dispersion and VCE modelling were carried out.

The mesh sensitivity study for the first step was carried out and is presented in Figure 6. Based on the mesh sensitivity study, a grid size of $1 \mathrm{~m}$ was employed for the dispersion simulation domain.

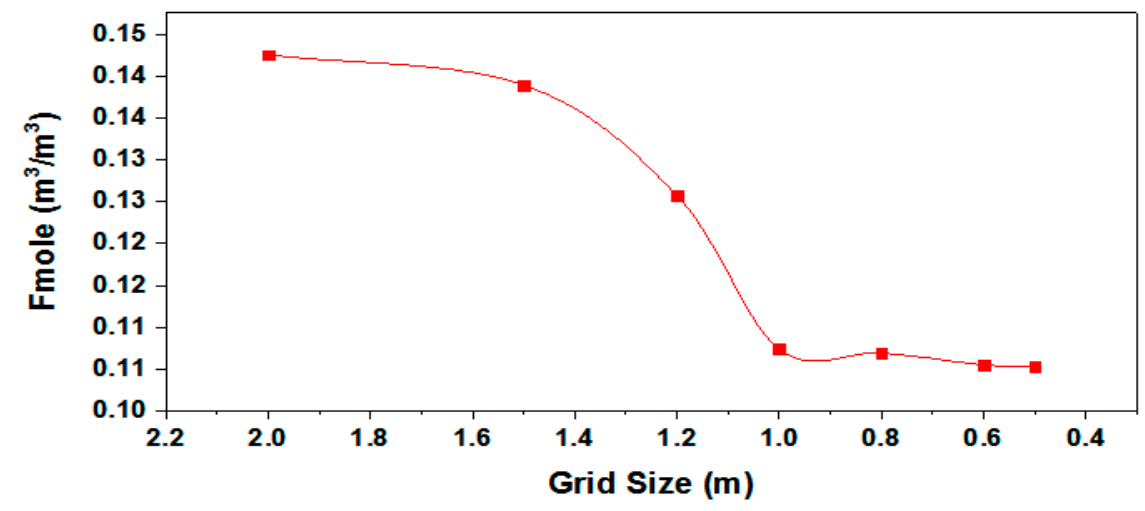

Figure 6. Dispersion mesh sensitivity study.

Similarly, a mesh sensitivity study for the second step (VCE simulation) was carried out and is presented in Figure 7. Based on the VCE mesh sensitivity study, a $0.6 \mathrm{~m}$ grid size was employed for the simulation domain. Default values of 5 and 0.5 were utilised for the Courant-Friedrich-Levy numbers, which are based on speed of sound (CFLC) and fluid velocity (CFLV), respectively [54].

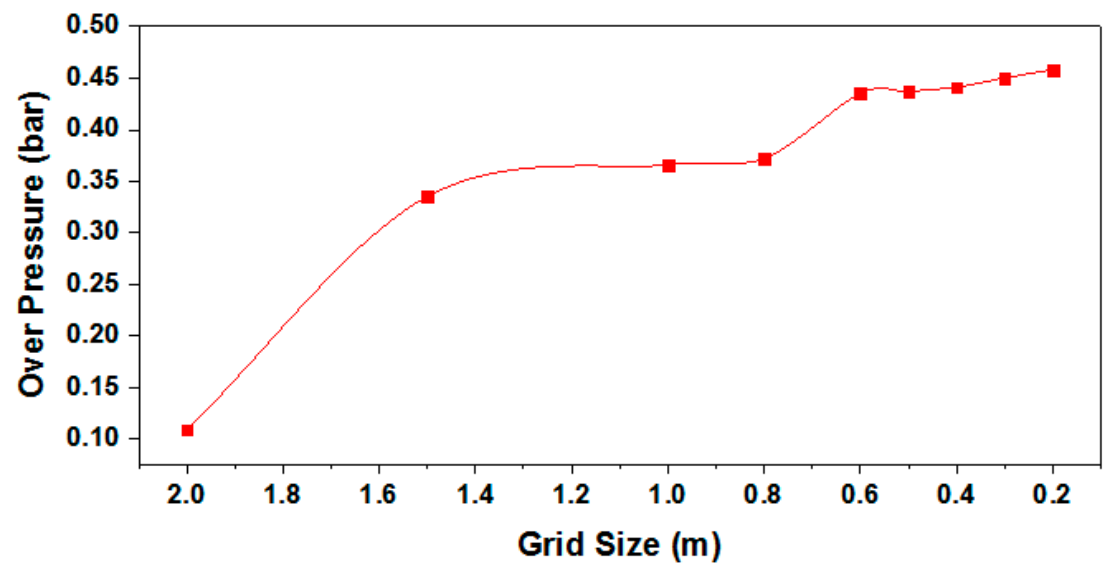

Figure 7. Vapour Cloud Explosion (VCE) mesh sensitivity study.

\subsubsection{VCE Simulation Considering Release of Methane Gas}

After carrying out the mesh sensitivity study, FLACS dispersion and VCE simulations were carried out, and overpressure resulting due to VCE at different parameters was estimated. Methane gas leak was assumed to occur from HP separator 1 as determined by HIRA. For FLACS dispersion simulation, wind boundary conditions were adopted at all inflow boundaries, and nozzle boundary conditions were selected for outflow boundaries [54]. Considering the flammability limit of methane 
gas (5-15\%), the flammable vapour cloud was ignited at $2 \mathrm{~min}$. Similarly, Euler boundary conditions were opted for VCE simulation as recommended by FLACS guidelines [54].

\subsection{Effect of Wind and Leakage Conditions on Human Fatality Risk Employing Grid-Based Approach}

After estimating the overpressure developed at different monitoring points, human fatality risk due to head impact, lung damage, and whole-body displacement was estimated at different years by employing Equation (10) and considering different wind speeds and leak rates for different leak directions. It is worth mentioning that the simulation results showed that leak direction RY+ and RZ+ showed no unacceptable risk of all fatalities. Therefore, the results presented in this section are for $\mathrm{RX}+, \mathrm{RY}-$, and RZ-.

Figure 8 displays the percentage affected area of unacceptable human fatality risk at year 1 for leak direction RX+. Parameters (wind speeds and leak rates) that have acceptable risk values are not presented for clarity.

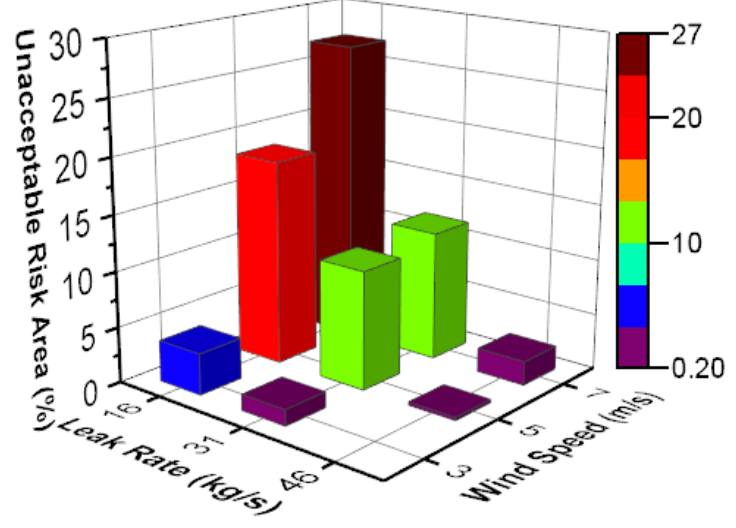

(a)

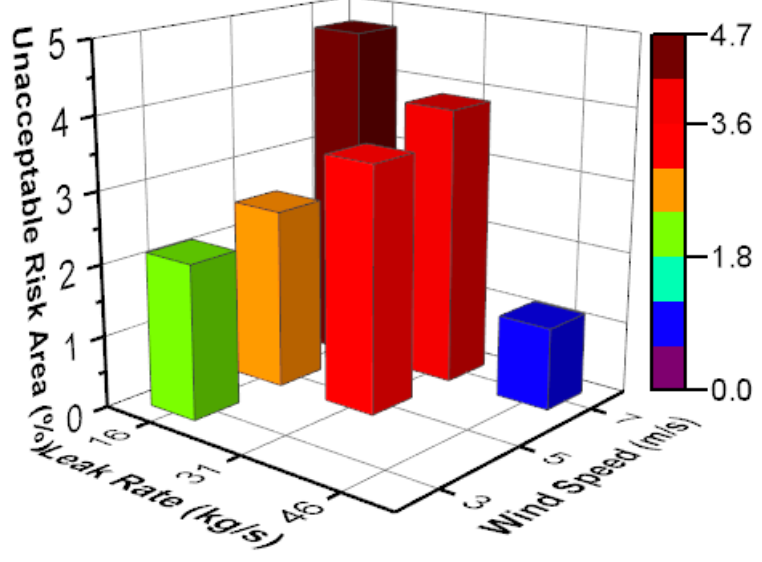

(b)

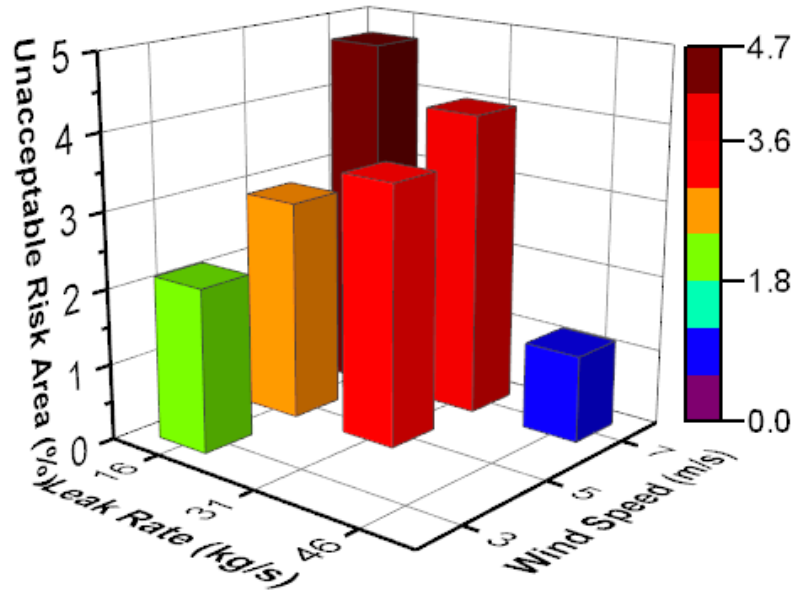

(c)

Figure 8. Unacceptable human fatality risk area for leak direction $R X+$ at year 1. (a) Head impact. (b) Lung damage. (c) Whole-body displacement.

Figure 8 a shows that the highest unacceptable risk area of $27 \%$ was measured for head impact at a wind speed of $7 \mathrm{~m} / \mathrm{s}$ and $16 \mathrm{~kg} / \mathrm{s}$ leak rate, while the lowest unacceptable risk area of $4.7 \%$ was recorded for lung damage and whole-body displacement, as shown in Figure $8 b, c$, respectively. Importantly, increasing the wind speed ( 3 to $7 \mathrm{~m} / \mathrm{s}$ ) caused a steady increase in risk values at all leak rates, whereby the head impact recorded a maximum increase of $21 \%$. In general, it is inferred that the 
highest risk areas were reported at $7 \mathrm{~m} / \mathrm{s}$ wind speed. Moreover, when the leak rate was increased (from 16 to $46 \mathrm{~kg} / \mathrm{s}$ ), the calculated unacceptable risk area decreased by $27 \%$ at a wind speed of $7 \mathrm{~m} / \mathrm{s}$, as presented in Figure 8a.

The parameters shown in Figure 9 are those that displayed unacceptable risk area for human fatality (head impact, lung damage, and whole body displacement) for RY- leak direction. It can be seen that the unacceptable risk area is low, whereas the highest recorded unacceptable risk area of head impact is $7.9 \%$ at a leak rate of $16 \mathrm{~kg} / \mathrm{s}$ and maximum wind speed of $7 \mathrm{~m} / \mathrm{s}$. The remaining leakage and wind conditions recorded below $2.5 \%$ unacceptable risk areas, which is relatively low.

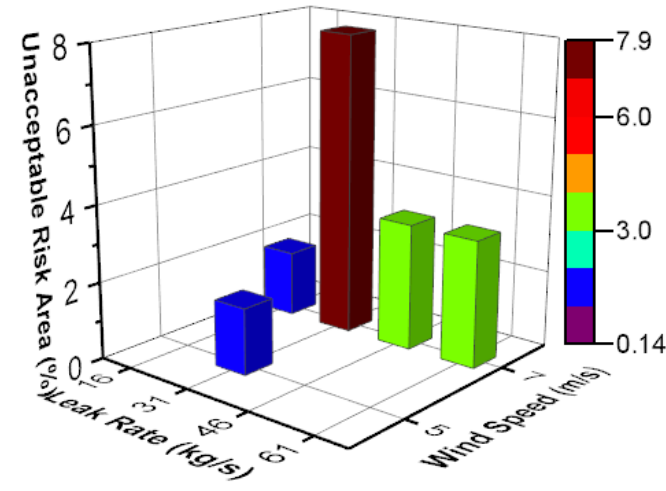

(a)

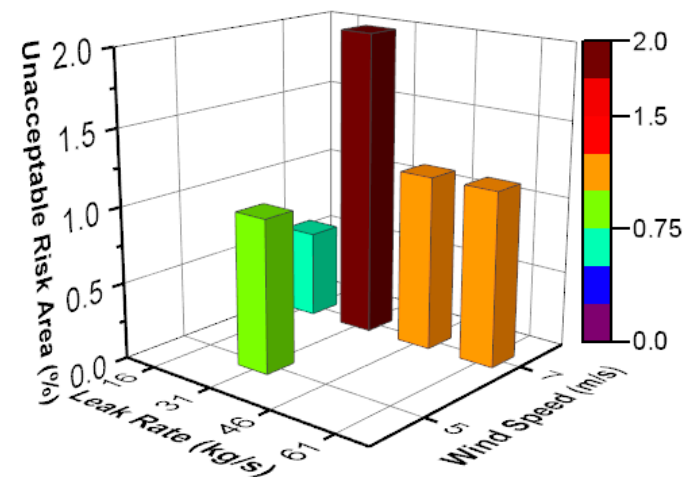

(b)

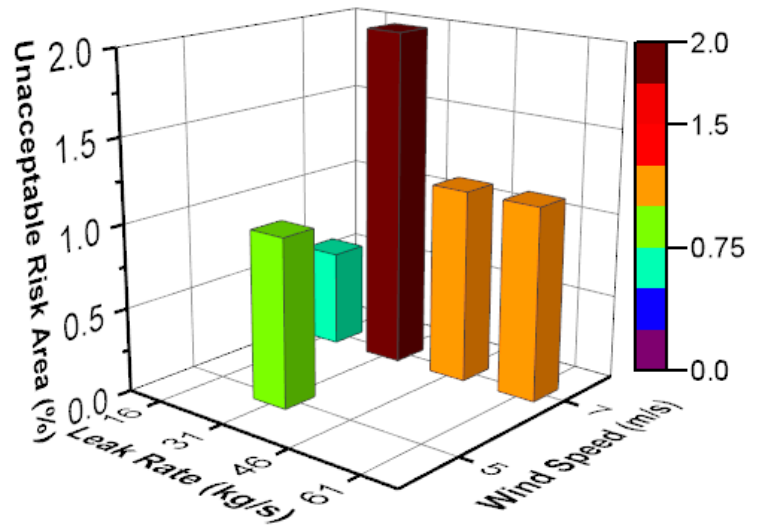

(c)

Figure 9. Unacceptable human fatality risk area for leak direction RY- at year 1. (a) Head impact.

(b) Lung damage. (c) Whole-body displacement.

Figure 10 demonstrates the impact of varying wind speed and leak rate on unacceptable human fatality risk areas for the RZ- leak direction. Similar to RY-, the results of unacceptable human fatality risk areas were low compared with the $\mathrm{RX}+$ leak direction. The highest recorded risk was $4.9 \%$ at $7 \mathrm{~m} / \mathrm{s}$ wind speed and $61 \mathrm{~kg} / \mathrm{s}$ leak rate for fatalities due to head impact. A smaller unacceptable risk area was recorded for lung damage and whole-body displacement, as shown in Figure 10b,c, respectively. Furthermore, similar to leak direction RY-, 3 m/s wind speed showed zero unacceptable fatality risk area.

The primary reason for different fatality risk values when wind speeds and leak rates were varied could be attributed to the concentration profile of the flammable methane-air mixture and interaction of flammable methane-air mixture with obstacles in the processing area of an offshore platform. The concentration of methane gas is one of imperative parameters for the development of overpressure $[58,59]$. By increasing the flammable methane-air concentration from $5 \%$ to $9.5 \%$ by volume gradually increases the overpressure, and achieves a maximum overpressure value at the stoichiometric concentration ( $9.5 \%$ by volume). Therefore, the overpressure due to VCE decreases from 
stoichiometric concentration ( $9.5 \%$ by volume) to high methane-air concentration ( $15 \%$ by volume) [58]. In addition, a flammable vapour cloud encountering more obstacles could lead to development of turbulent flow regimes, resulting in expanding the flame surface, which may lead to higher combustion rate and hence higher overpressure [60-62].

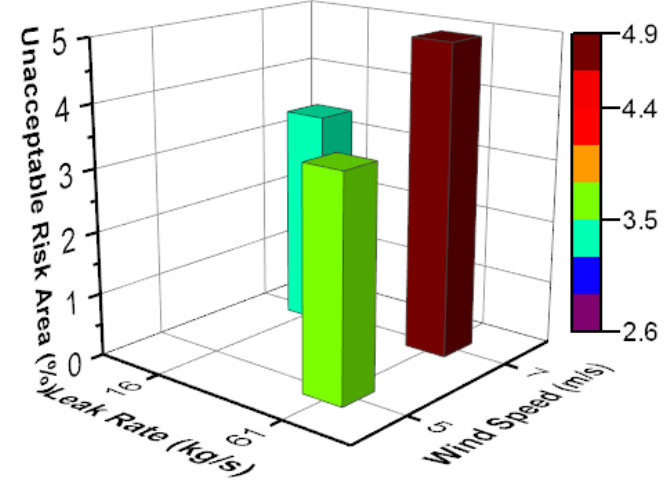

(a)

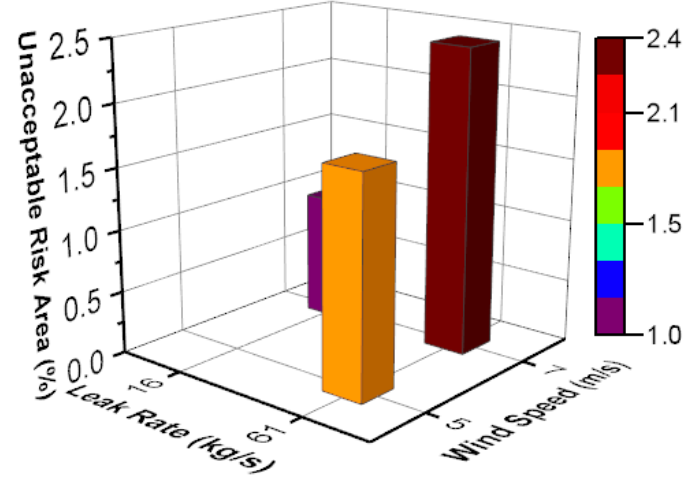

(b)

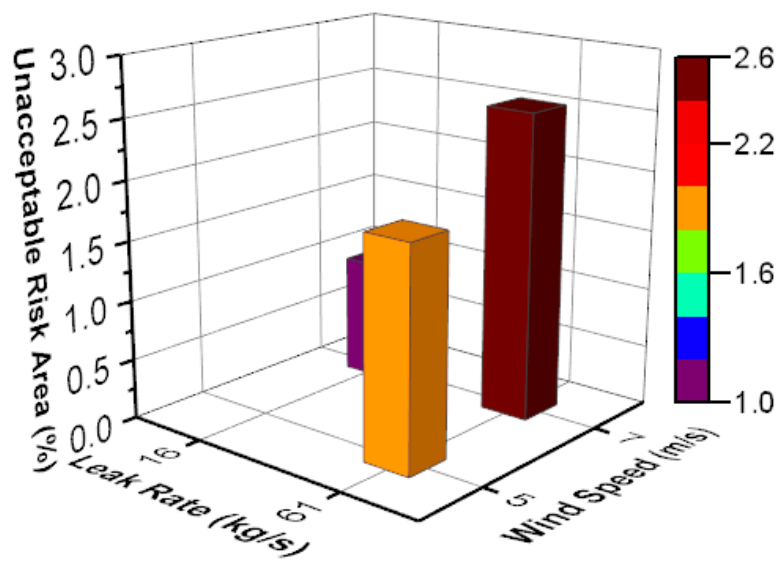

(c)

Figure 10. Unacceptable human fatality risk area for leak direction RZ- at year 1. (a) Head impact. (b) Lung damage. (c) Whole-body displacement.

Figure 11 displays the concentration profile of methane-air mixture and overpressure developed due to VCE at low and high wind speeds and $31 \mathrm{~kg} / \mathrm{s}$ leak rate for leak direction RX+. The methane-air mixture is mostly rich, with a concentration of $15 \%$ and above at wind speed of $3 \mathrm{~m} / \mathrm{s}$, as presented in Figure 11a, which caused low overpressure development, as seen in Figure 11b. Therefore, the unacceptable risk area of fatality due to head impact was reported to be low, as shown in Figure 8 a. However, at a higher wind speed of $7 \mathrm{~m} / \mathrm{s}$, the methane-air mixture is dispersed into more areas of the processing deck, thereby encountering more obstacles, as shown in Figure 11c.

In addition, an increase in wind speed to $7 \mathrm{~m} / \mathrm{s}$ caused a large portion of the methane-air mixture to be within the concentration range of $5-12 \%$, which resulted in higher overpressure, as shown in Figure 11d. Consequently, the unacceptable risk area for fatality increased (11.6\% head impact), as shown in Figure 8a.

For leak direction $\mathrm{RX}+$, a decrease in risk values for human fatality was recorded with the increase in leak rate, which is attributed to methane-air mixture concentration profile. As seen in Figure 12a, a considerable portion of the flammable methane-air mixture was within the concentration range of $10-12 \%$, which is near the methane-air concentration of $9.5 \%$ that resulted in high overpressure, as shown in Figure 12b. Consequently, 6.8\% area recorded unacceptable risk due to head impact, as shown in Figure 8a. 


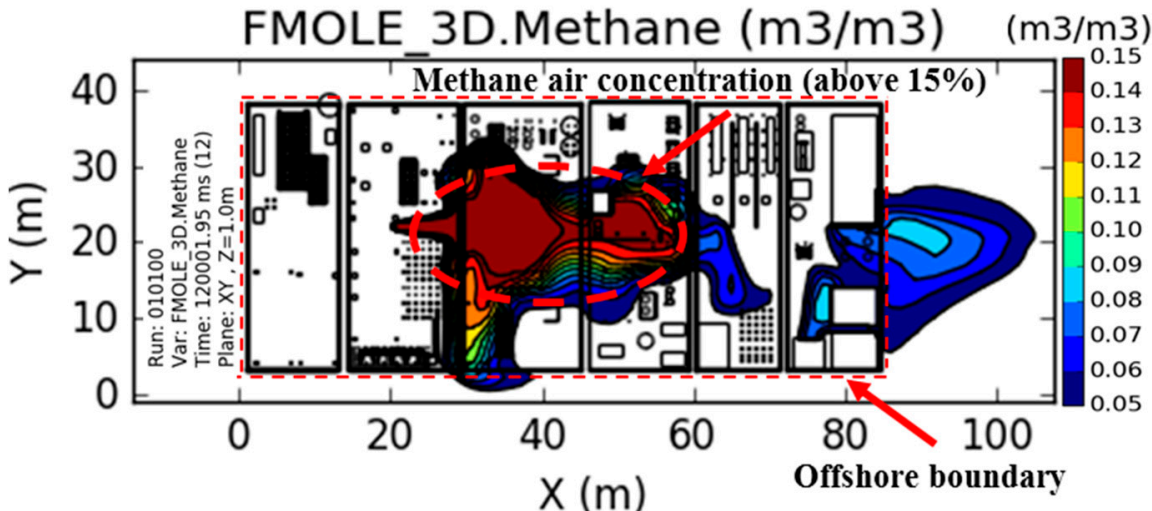

(a)

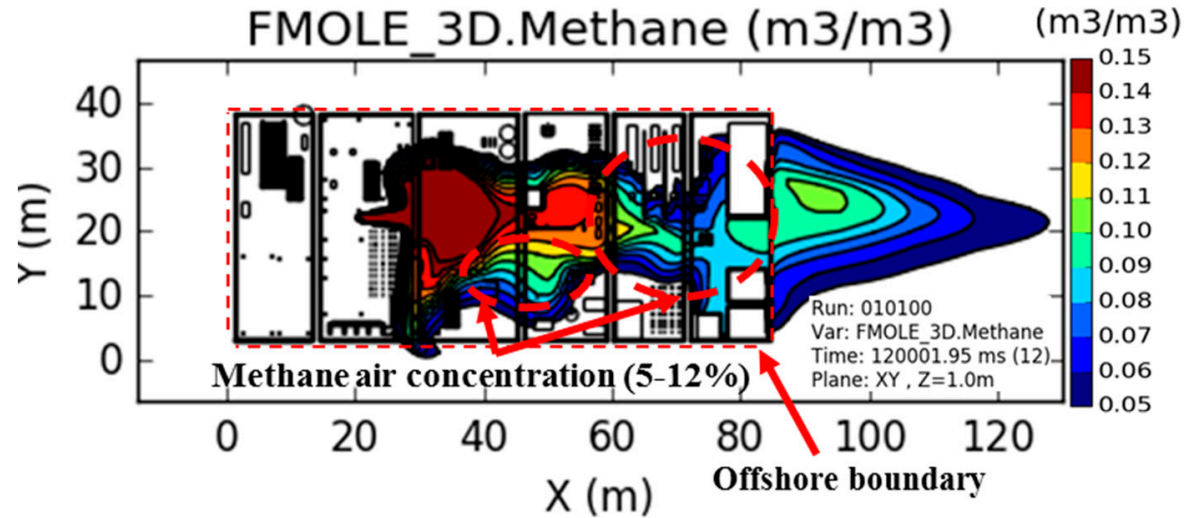

(c)

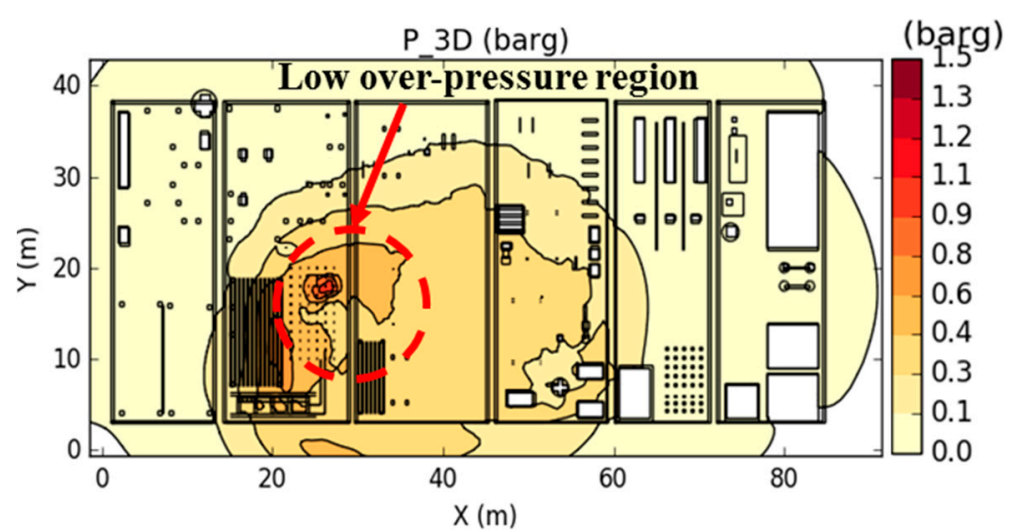

(b)

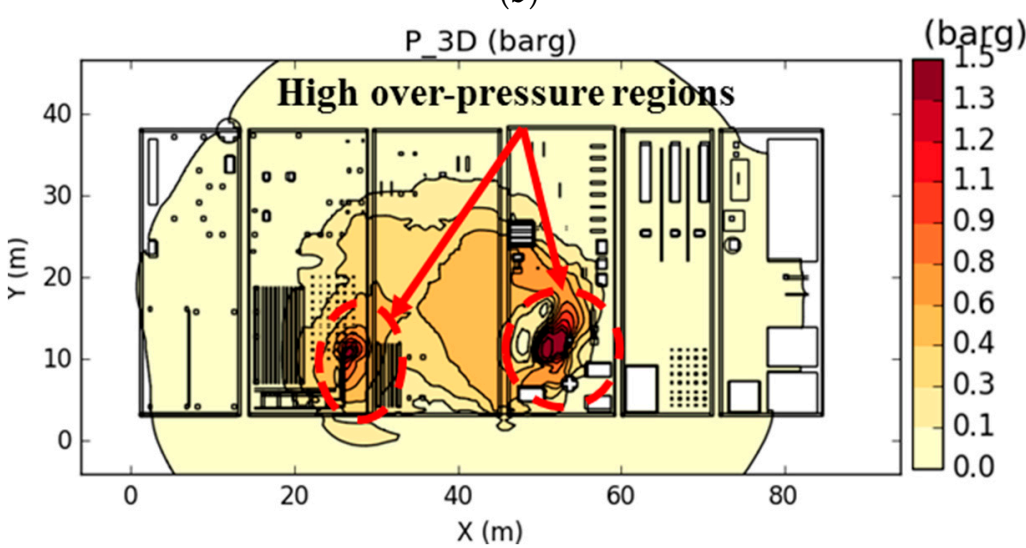

(d)

Figure 11. Methane-air concentration and VCE overpressure contours at $31 \mathrm{~kg} / \mathrm{s}$ leak rate and RX+ leak direction. (a) Concentration profile of methane-air mixture at wind speed of $3 \mathrm{~m} / \mathrm{s}$. (b) Overpressure contour at wind speed of $3 \mathrm{~m} / \mathrm{s}$. (c) Concentration profile of methane-air mixture at wind speed of $7 \mathrm{~m} / \mathrm{s}$. (d) Overpressure contour at wind speed of $7 \mathrm{~m} / \mathrm{s}$. 


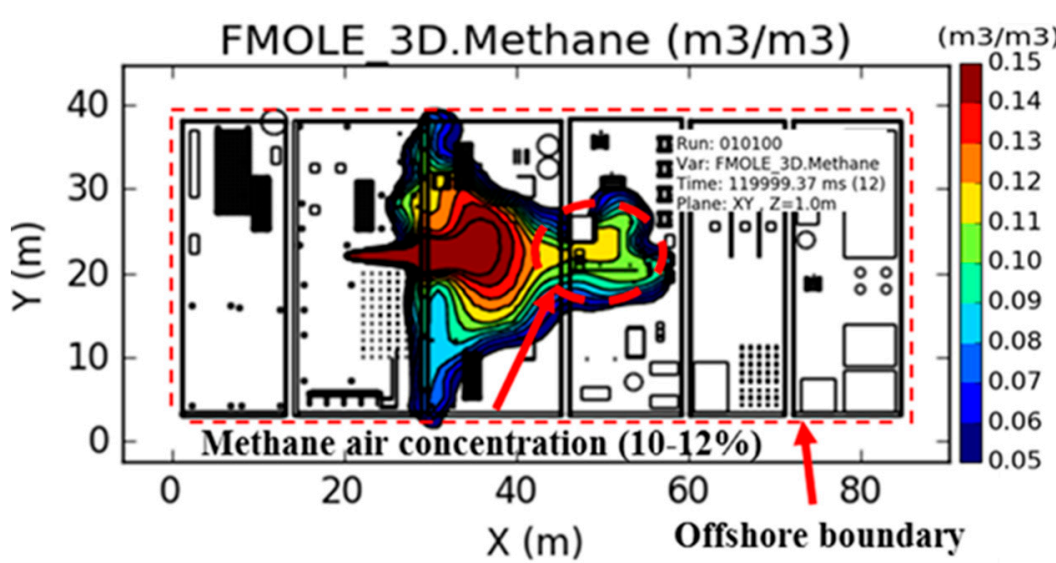

(a)

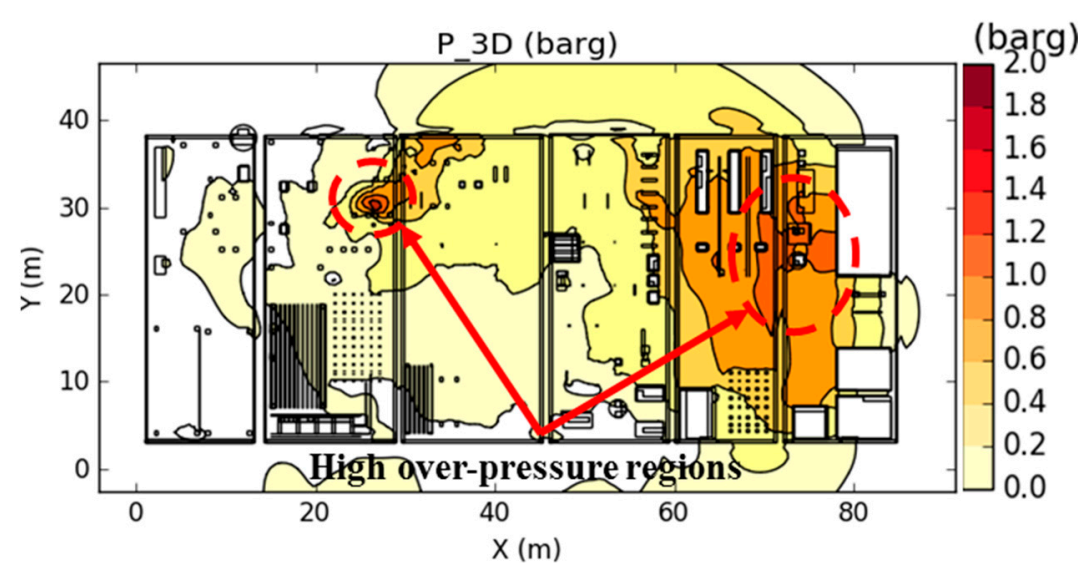

(b)

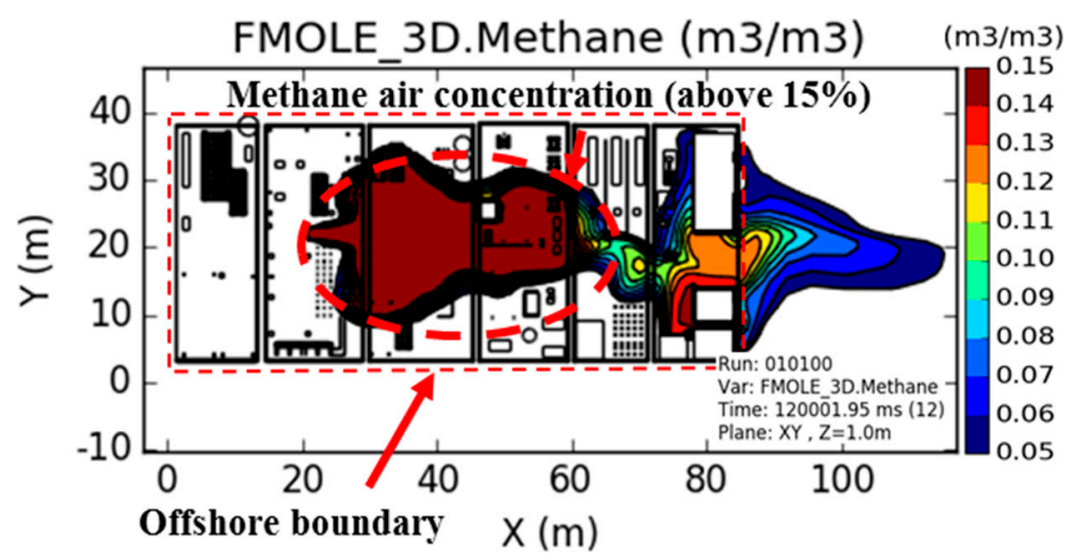

(c)

Figure 12. Methane-air concentration profile and overpressure by VCE for RX+ leak direction and wind speed of $3 \mathrm{~m} / \mathrm{s}$. (a) Concentration profile of methane-air mixture at $16 \mathrm{~kg} / \mathrm{s}$ leak rate. (b) Overpressure contour at $16 \mathrm{~kg} / \mathrm{s}$ leak rate. (c) Concentration profile of methane-air mixture at $61 \mathrm{~kg} / \mathrm{s}$ leak rate. 
However, at $61 \mathrm{~kg} / \mathrm{s}$ leak rate, although the quantity of fuel released was higher, a large portion of the methane-air mixture was close to and above the rich region of a methane-air mixture, as shown in Figure 12c, thereby contributing to the development of almost zero overpressure. Accordingly, zero unacceptable risk area of head impact was observed (Figure 8a).

It can be concluded that increasing the wind speed from 3 to $7 \mathrm{~m} / \mathrm{s}$ resulted in increasing the risk values. Furthermore, the results also showed that leak direction $\mathrm{RX}+$ recorded higher risk values as compared to other leak directions. Moreover, RY+ and RZ+ leak directions reported zero unacceptable risk values for all wind speeds and leak rates.

\subsection{Utilising a Grid-Based Appraoch for Dynamic Human Fatality Risk}

As mentioned earlier, the $\mathrm{RX}+$ leak direction reported the highest risk values for different human fatalities; therefore, it has been selected to present the risk variation with respect to time. The risk at year 3 and year 5 are considered here to present the dynamic risk by incorporating updated probabilities of high-pressure release by employing Equation 10 as shown in Figure 13. Risk at year 1 is not shown here because it has been already presented in Figure 8 .

Figure 13 shows that the unacceptable risk area continues to increase over time. As seen in Figure 13a,c,e, at year 3, the maximum unacceptable risk area for head impact, lung damage, and whole-body displacement was recorded to be $33.5 \%, 8 \%$, and $10 \%$ of the total area, respectively. However, at year 5 , it could be noted that the unacceptable risk area increased to $35 \%$, $9 \%$, and $15 \%$ of the total area, as shown in Figure 13b,d,f.

As mentioned earlier, a grid-based approach has the advantage of providing microlevel details of risk variation at any specified area. To present the dynamic risk estimation results using this approach, the $\mathrm{RX}+$ leak direction at $16 \mathrm{~kg} / \mathrm{s}$ leak rate with $3 \mathrm{~m} / \mathrm{s}$ wind speed was selected, thereby displaying the transient risk variation at years 1 and 5, as displayed in Figure 14.

The above-mentioned case is selected to present how this framework estimates and presents dynamic risk variation of human fatality with respect to time and shows the locations of high risk. For this case, it could be seen from Figures 8 and 13 that the areas of unacceptable risk of human fatality increased from $3.7 \%$ to $7.6 \%, 2.2 \%$ to $4 \%$, and $2.2 \%$ to $5 \%$ for head impact, lung damage, and whole-body displacement, respectively.

Figure 14a,c,e show that the unacceptable human fatality risk due to head impact, lung damage, and whole body displacement was present at year 1 . However, the unacceptable risk area was reported low. At year 5, Figure $14 b, d, f$ show that the areas where the risk of human fatalities were tolerable at year 1 , were no longer acceptable after 4 years.

It is worth mentioning that the green circled areas in Figure $14 b, d, f$ represent the areas where the risk increased from year 1 to year 5 ; however, it remained within the acceptable risk limit. These areas could be considered as vulnerable areas in which the risk could reach the unacceptable limit beyond 5 years. The proposed grid-based approach helped to visualise how the risk of human fatality changed with time. 


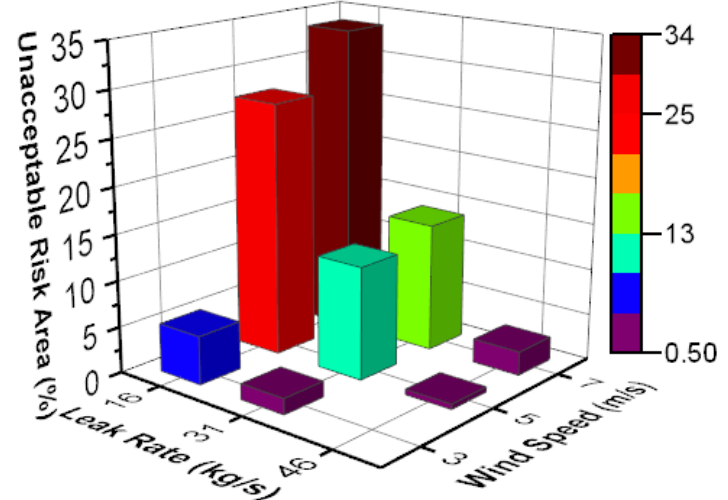

(a)

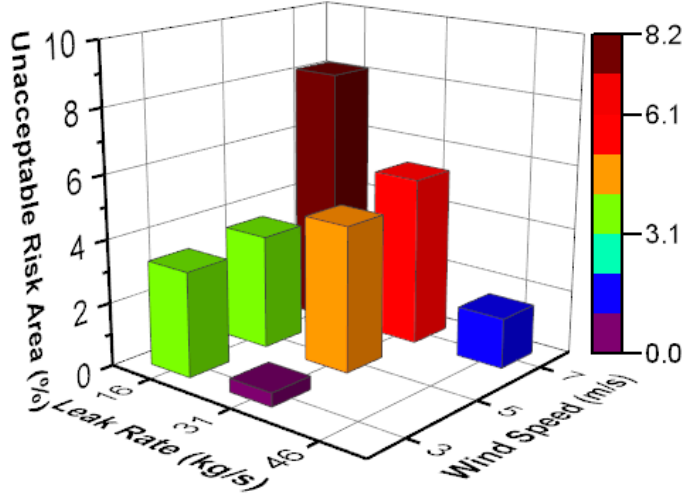

(c)

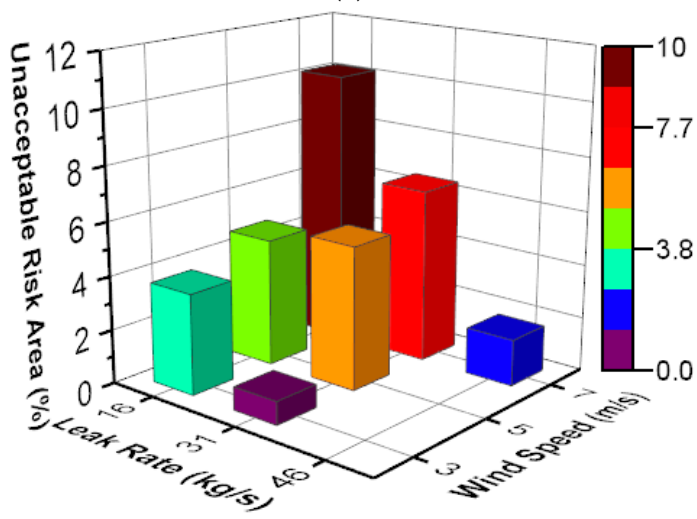

(e)

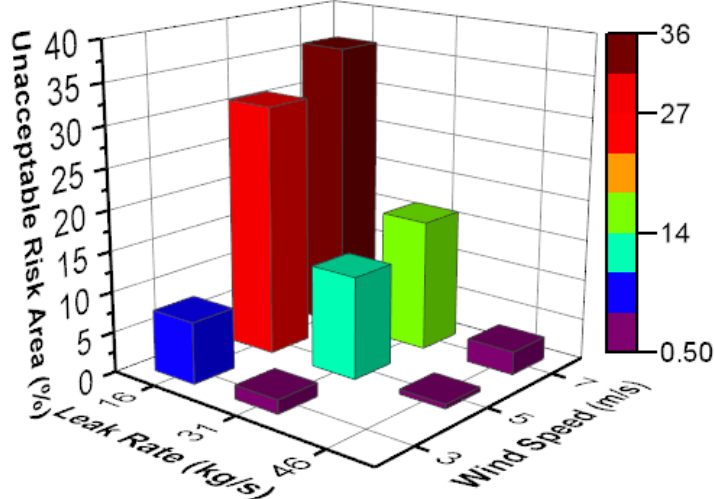

(b)

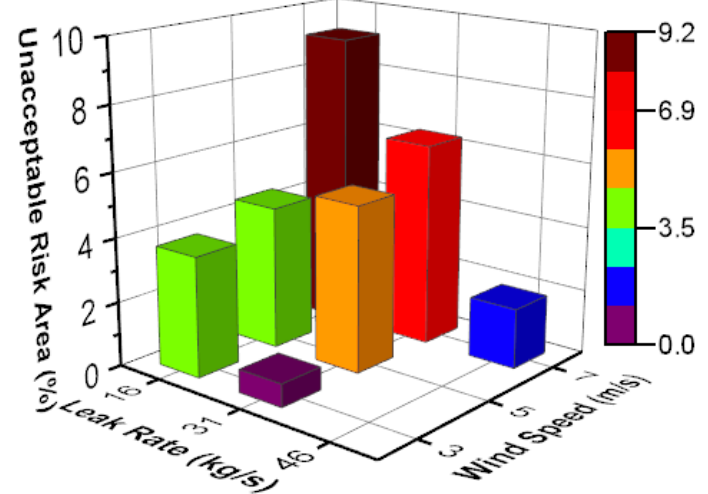

(d)

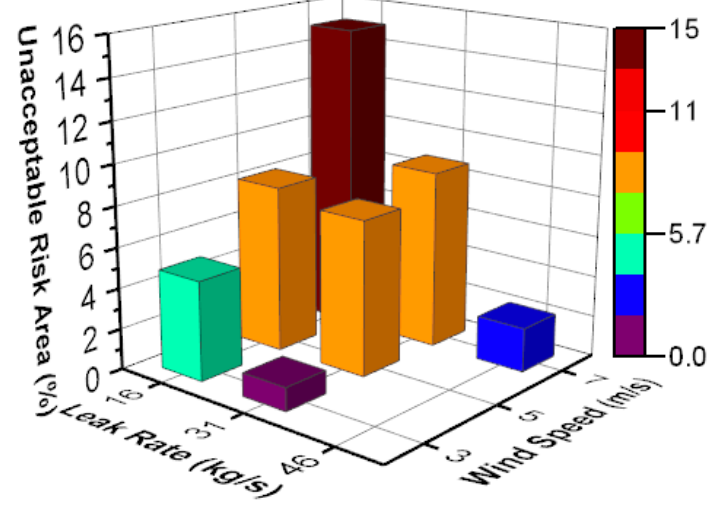

(f)

Figure 13. Unacceptable human fatality risk percentage area for leak direction $R X+$ at different years. (a) Head impact at year 3. (b) Head impact at year 5. (c) Lung damage at year 3. (d) Lung damage at year 5. (e) Whole-body displacement at year 3. (f) Whole-body displacement at year 5. 


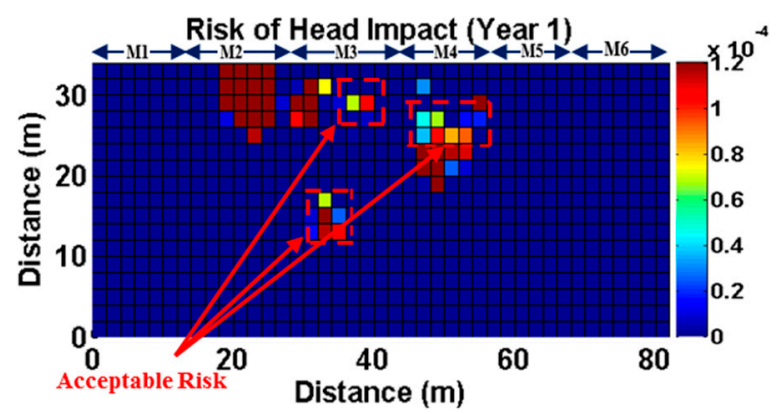

(a)

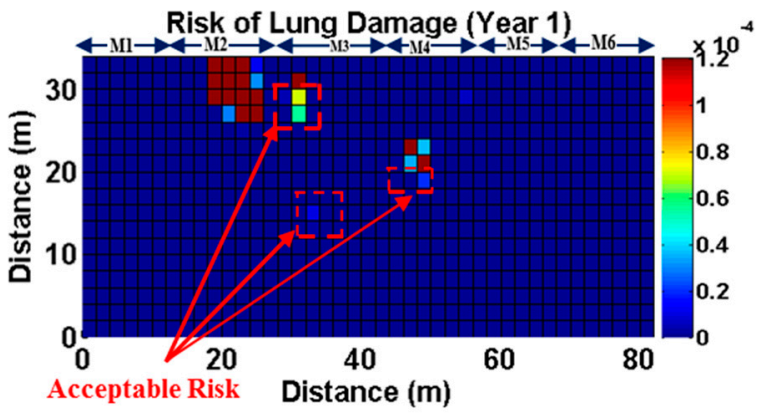

(c)

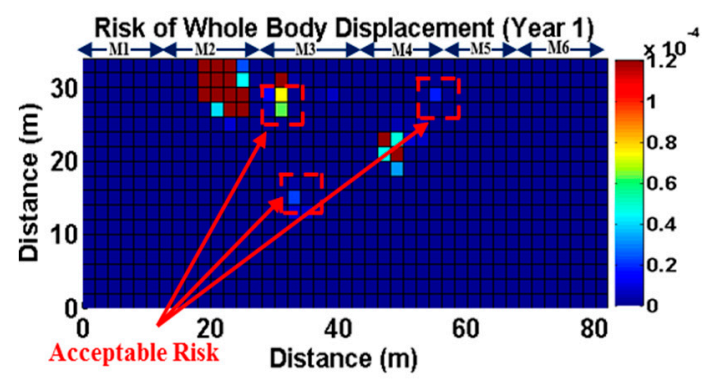

(e)

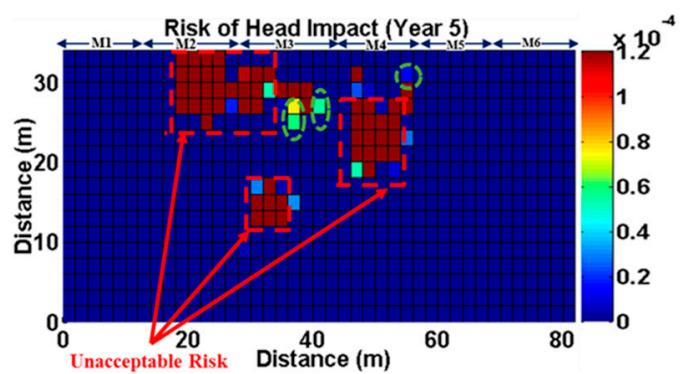

(b)

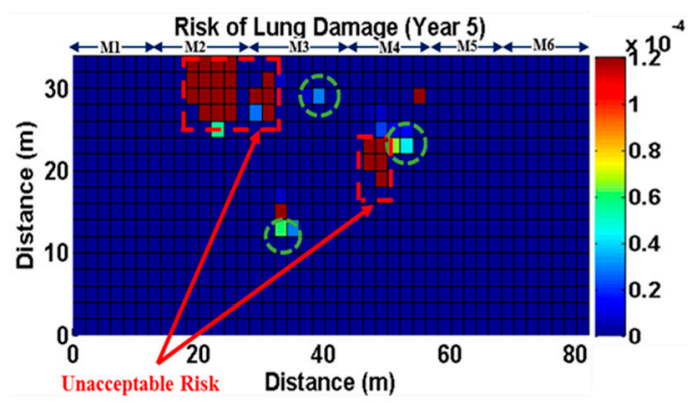

(d)

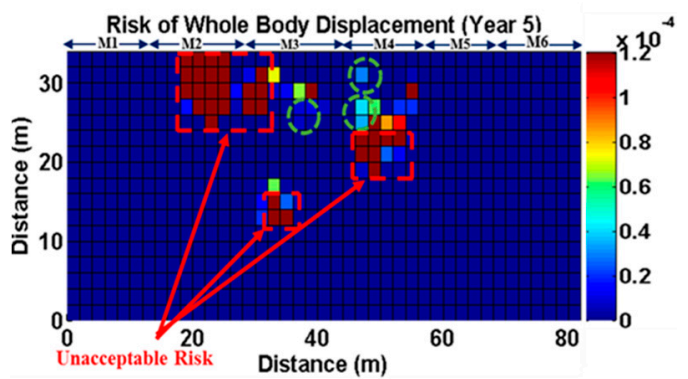

(f)

Figure 14. Dynamic risk of a human fatality at different years at $16 \mathrm{~kg} / \mathrm{s}$ leak rate of $16 \mathrm{~kg} / \mathrm{s}$ with $3 \mathrm{~m} / \mathrm{s}$ wind speed. (a) Risk of head impact at year 1. (b) Risk of head impact at year 5. (c) Risk of lung damage at year 1. (d) Risk of lung damage at year 5. (e) Risk of whole-body displacement at year 1. (f) Risk of whole-body displacement at year 5 .

\subsection{Identification of the Most Affected Area}

A total of 60 cases were simulated using the grid-based approach based on different wind speeds, leak directions and leak rates. By analysing all cases, it was found that irrespective of different parameters (leak rate, leak direction, and wind speed) affecting the developed overpressure due to VCE, areas near HP separator 1, the metering skid, and well manifold are highly vulnerable areas (Figure 15) that always recorded the highest risk of human fatality; therefore, implementing measures to reduce the risk in these areas is necessary.

From the above dynamic risk analysis, it could be concluded that the proposed GDRA framework provided a risk picture of the processing unit both spatially and temporally. From the detailed results and analysis of methane concentration and pressure contours and risk grids, this framework determined the areas of highest risk. By analysing the results, we were able to conclude that the $\mathrm{RX}+$ leak direction recorded the highest risk at wind speed and leak rate of $7 \mathrm{~m} / \mathrm{s}$ and $16 \mathrm{~kg} / \mathrm{s}$, respectively. Other leak directions recorded very low unacceptable risk areas. 


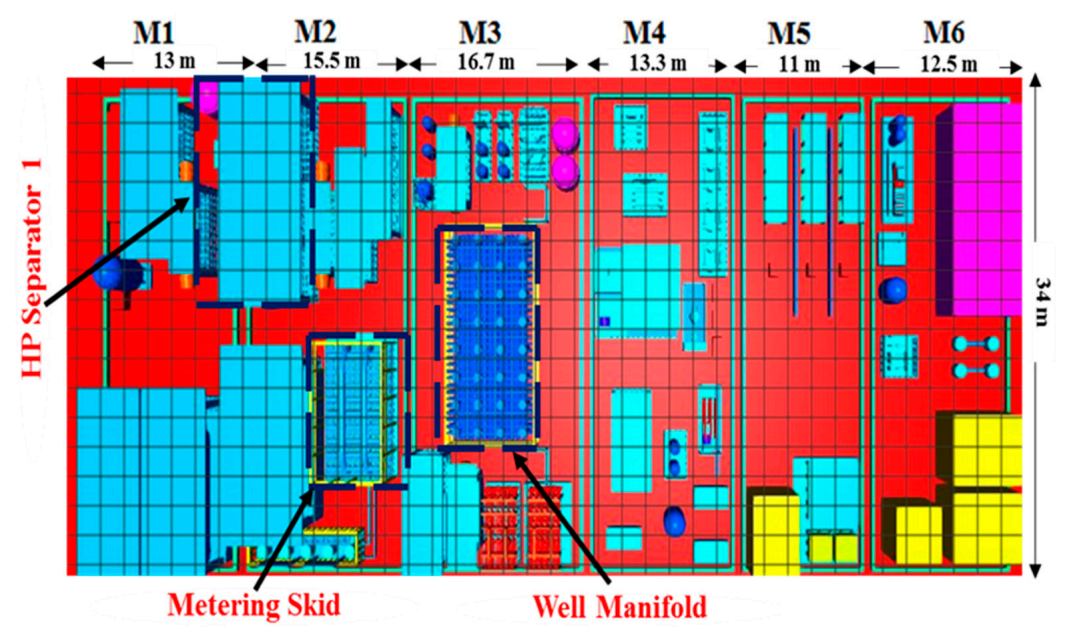

Figure 15. Most dangerous areas in terms of human fatality risk.

This framework also presented the variation of human fatality risk with respect to time, and successfully determined the dynamic risk from year 1 to year 5 . By considering the highest risk case scenario $(7 \mathrm{~m} / \mathrm{s}$ wind speed and $16 \mathrm{~kg} / \mathrm{s}$ leak rate), it was found that an increase of $25 \%, 48 \%$, and $68 \%$ in unacceptable risk area from year 1 to year 5 was recorded for head impact, lung damage, and whole-body displacement, respectively.

This was achieved by continuously updating the probability of VCE, which was accomplished by incorporating near misses and incidents data (ASP data) using BI with respect to time. Hence, the transient change in risk profiles with respect to time of different human fatalities are captured at each grid within the processing area. The framework showed the advantage of determining the risk values at specified locations within the grids. The variation of risk was presented at each grid, enabling precise determination of risk at specific locations so that risk mitigation measures can be implemented to reduce the human fatality risk.

\section{Conclusions}

In this study, a GDRA methodology is proposed to analyse microlevel VCE risk assessment. The VCE impact is assessed as human fatality caused by head impact, lung damage, and whole-body displacement. BI is employed to update the probability of the different consequences of the accident with ASP data. FLACS is used to model the high pressure release of methane gas, resulting dispersion, and VCE at different wind speeds, leak rates, and leak directions. For risk representation, a grid-based approach is adopted; it incorporated location-specific details and enabled enhanced risk screening of human fatalities. In addition, the effects of leak rate, leak direction, and wind speed on human fatality risk were investigated.

The application of the methodology confirmed its usability as an efficient and reliable decision-making tool. Based on the results of different wind and leakage conditions, it was established that the $\mathrm{RX}+$ leak direction had the highest unacceptable risk area, where $36 \%$ risk was recorded. It also showed that with the increase in wind speed, the human fatality risk increases. However, increasing the leak rate for a specific wind speed resulted in a decrease in human fatality risk. In addition, the proposed framework provides dynamic risk estimation of different human fatalities using ASP data and the BI mechanism. By integration with a grid-based approach, the tool provides a risk picture of the deck, both spatially and temporally. Moreover, the current study highlights the most dangerous locations in terms of human fatality risk. This research will assist in the identification of vulnerable areas on deck, and help in the formulation of appropriate corrective actions.

Author Contributions: Conceptualization, U.M.N., M.S.N., M.M. and F.K.; methodology U.M.N., M.S.N., and M.M.; formal analysis, U.M.N. and M.S.N.; investigation, U.M.N., and M.S.N.; writing-original draft 
preparation, U.M.N.; writing-review and editing, U.M.N., M.S.N., and F.K.; supervision, M.S.N., and M.M.; funding acquisition, M.S.N. All authors have read and agreed to the published version of the manuscript.

Funding: This research was funded by Yayasan Universiti Teknologi PETRONAS (YUTP), grant number 015LC0-159.

Acknowledgments: The authors would like to acknowledge the financial assistant to the first author provided by Universiti Teknologi PETRONAS through its Graduate Assistantship Scheme.

Conflicts of Interest: All authors declare no conflict of interest.

\section{Nomenclature}

$\begin{array}{ll}p n & \text { Penalties } \\ H_{c} & \text { Heat of combustion }(\mathrm{KJ} / \mathrm{kg}) \\ \boldsymbol{M} & \text { Mass release rate }(\mathrm{kg} / \mathrm{s}) \text { or Mass of fuel }(\mathrm{kg}) \\ \text { V } & \text { Volume of equipment }\left(\mathrm{m}^{3}\right) \\ \text { DP } & \text { Damage Potential } \\ \text { OT } & \text { Operating Temperature }\left({ }^{\circ} \mathrm{C}\right) \\ \text { FRP } & \text { Fire Point }\left({ }^{\circ} \mathrm{C}\right) \\ \text { PP } & \text { Processing Pressure }(\mathrm{kPa}) \\ \text { AP } & \text { Atmospheric Pressure }(\mathrm{kPa}) \\ \text { VP } & \text { Vapour Pressure }(\mathrm{kPa}) \\ \text { K } & \text { Constant }(3148) \\ \text { F1, F2, F3 } & \text { Chemical and Physical Energy Factors } \\ \text { NF } & \text { NFPA ranking (flammability) } \\ \text { NR } & \text { NFPA ranking (reactivity) } \\ \text { FEDI } & \text { Fire and Explosion Damage Index } \\ \text { LT } & \text { Level Transmitter } \\ \text { LIC } & \text { Level Indicator Controller } \\ \text { LCV } & \text { Level Control Valve } \\ \text { HLA } & \text { High Level Alarm } \\ \text { PT } & \text { Pressure Transmitter } \\ \text { PIC } & \text { Pressure Indicator Controller } \\ \text { PCV } & \text { Pressure Control Valve } \\ \text { PSV } & \text { Eressure Safety Valve } \\ \text { HPA } & \text { Emergency Shutdown Valve } \\ \text { ESD } & \end{array}$

\section{References}

1. Adedigba, S.A.; Khan, F.; Yang, M. Dynamic failure analysis of process systems using neural networks. Process Saf. Environ. Prot. 2017, 111, 529-543. [CrossRef]

2. Park, S.; Jeong, B.; Lee, B.S.; Oterkus, S.; Zhou, P. Potential risk of vapour cloud explosion in FLNG liquefaction modules. Ocean. Eng. 2018, 149, 423-437. [CrossRef]

3. Baalisampang, T.; Abbassi, R.; Garaniya, V.; Khan, F.; Dadashzadeh, M. Fire impact assessment in FLNG processing facilities using Computational Fluid Dynamics (CFD). Fire Saf. J. 2017, 92, 42-52. [CrossRef]

4. Krueger, J.; Smith, D. A practical approach to fire hazard analysis for offshore structures. J. Hazard. Mater. 2003, 104, 107-122. [CrossRef]

5. UK, HSE. Accident Statistics for Floating Offshore Units on the UK Continental Shelf (1980-2003); HMSO RR 353: Hovik, Norway, 2005.

6. Kang, K.-Y.; Choi, K.-H.; Choi, J.; Ryu, Y.; Lee, J.-M. Dynamic response of structural models according to characteristics of gas explosion on topside platform. Ocean. Eng. 2016, 113, 174-190. [CrossRef]

7. Paé-Cornell, M. Learning from the Piper Alpha accident: A postmortem analysis of technical and organizational factors. Insur. Math. Econ. 1993, 13, 165. [CrossRef]

8. Atherton, J.; Gil, F. Incidents That Define Process Safety; Wiley Online Library: Hoboken, NJ, USA, 2008.

9. Dadashzadeh, M.; Abbassi, R.; Khan, F.; Hawboldt, K. Explosion modeling and analysis of BP Deepwater Horizon accident. Saf. Sci. 2013, 57, 150-160. [CrossRef] 
10. Le Coze, J.C. What have we learned about learning from accidents? Post-disasters reflections. Saf. Sci. 2013, 51, 441-453. [CrossRef]

11. Kalantarnia, M.; Khan, F.; Hawboldt, K. Dynamic risk assessment using failure assessment and Bayesian theory. J. Loss Prev. Process Ind. 2009, 22, 600-606. [CrossRef]

12. Paltrinieri, N.; Khan, F. Dynamic Risk Analysis in the Chemical and Petroleum Industry: Evolution and Interaction with Parallel Disciplines in the Perspective of Industrial Application; Butterworth-Heinemann: Oxford, UK, 2016.

13. Villa, V.; Paltrinieri, N.; Khan, F.; Cozzani, V. Towards dynamic risk analysis: A review of the risk assessment approach and its limitations in the chemical process industry. Saf. Sci. 2016, 89, 77-93. [CrossRef]

14. Khan, F.; Hashemi, S.J.; Paltrinieri, N.; Amyotte, P.; Cozzani, V.; Reniers, G. Dynamic risk management: A contemporary approach to process safety management. Curr. Opin. Chem. Eng. 2016, 14, 9-17. [CrossRef]

15. Pula, R.; Khan, F.; Veitch, B.; Amyotte, P. A grid based approach for fire and explosion consequence analysis. Process Saf. Environ. Prot. 2006, 84, 79-91. [CrossRef]

16. Abimbola, M.; Khan, F.; Khakzad, N. Dynamic safety risk analysis of offshore drilling. J. Loss Prev. Process Ind. 2014, 30, 74-85. [CrossRef]

17. Li, X.; Chen, G.; Khan, F.; Xu, C. Dynamic risk assessment of subsea pipelines leak using precursor data. Ocean. Eng. 2019, 178, 156-169. [CrossRef]

18. Meng, X.; Chen, G.; Zhu, G.; Zhu, Y. Dynamic quantitative risk assessment of accidents induced by leakage on offshore platforms using DEMATEL-BN. Int. J. Nav. Archit. Ocean. Eng. 2019, 11, 22-32. [CrossRef]

19. Kalantarnia, M.; Khan, F.; Hawboldt, K. Modelling of BP Texas City refinery accident using dynamic risk assessment approach. Process Saf. Environ. Prot. 2010, 88, 191-199. [CrossRef]

20. Meel, A.; Seider, W.D. Plant-specific dynamic failure assessment using Bayesian theory. Chem. Eng. Sci. 2006, 61, 7036-7056. [CrossRef]

21. Khakzad, N.; Khan, F.; Amyotte, P. Dynamic risk analysis using bow-tie approach. Reliab. Eng. Syst. Saf. 2012, 104, 36-44. [CrossRef]

22. Adedigba, S.A.; Oloruntobi, O.; Khan, F.; Butt, S. Data-driven dynamic risk analysis of offshore drilling operations. J. Pet. Sci. Eng. 2018, 165, 444-452. [CrossRef]

23. Qiao, A.; Zhang, S. Advanced CFD modeling on vapour dispersion and vapour cloud explosion. J. Loss Prev. Process Ind. 2010, 23, 843-848. [CrossRef]

24. Baron, N.; Buchwald, C.R. Suppression of overpressure during a vapour cloud explosion-A new approach. Process Saf. Prog. 2017, 36, 54-61. [CrossRef]

25. Atkinson, G.; Cowpe, E.; Halliday, J.; Painter, D. A review of very large vapour cloud explosions: Cloud formation and explosion severity. J. Loss Prev. Process Ind. 2017, 48, 367-375. [CrossRef]

26. Hansen, O.R.; Gavelli, F.; Davis, S.G.; Middha, P. Equivalent cloud methods used for explosion risk and consequence studies. J. Loss Prev. Process Ind. 2013, 26, 511-527. [CrossRef]

27. Dadashzadeh, M.; Khan, F.; Hawboldt, K.; Amyotte, P. An integrated approach for fire and explosion consequence modelling. Fire Saf. J. 2013, 61, 324-337. [CrossRef]

28. Baalisampang, T.; Abbassi, R.; Garaniya, V.; Khan, F.; Dadashzadeh, M. Modelling an integrated impact of fire, explosion and combustion products during transitional events caused by an accidental release of LNG. Process Saf. Environ. Prot. 2019, 128, 259-272. [CrossRef]

29. Zhang, Q.; Zhou, G.; Hu, Y.; Wang, S.; Sun, B.; Yin, W.; Guo, F. Risk evaluation and analysis of a gas tank explosion based on a vapour cloud explosion model: A case study. Eng. Fail. Anal. 2019, 101, 22-35. [CrossRef]

30. Seo, J.; Bae, S. An approach to grid-based fire frequency analysis for design accidental loads in offshore installations. J. Appl. Mech. Eng. 2016, 5, 1-7.

31. Zohdirad, H.; Ebadi, T.; Givehchi, S.; Meysami, H. Grid-based individual risk calculation in the classification of hazardous area with a risk-based approach. J. Loss Prev. Process Ind. 2016, 43, 98-105. [CrossRef]

32. Huang, Y.; Ma, G.; Li, J. Grid-based risk mapping for gas explosion accidents by using Bayesian network method. J. Loss Prev. Process. Ind. 2017, 48, 223-232. [CrossRef]

33. Niazi, U.M.; Nasif, M.S.; Muhammad, M. Effect of wind directions on human injury and fatality risk modeling due to vapour cloud explosion in offshore platforms. Process Saf. Prog. 2020, 39, e12123. [CrossRef]

34. Huang, Y.; Ma, G. A grid-based risk screening method for fire and explosion events of hydrogen refuelling stations. Int. J. Hydrog. Energy 2018, 43, 442-454. [CrossRef]

35. HSE. Offshore accident/Incident Statistics Reports, OTO96. 954; Health and Safety Executive: London, UK, 1996. 
36. Khan, F.I.; Abbasi, S. Multivariate hazard identification and ranking system. Process Saf. Prog. 1998, 17, 157-170. [CrossRef]

37. Taylor, J. Automated HAZOP revisited. Process Saf. Environ. Prot. 2017, 111, 635-651. [CrossRef]

38. Kalantarnia, M. Dynamic Risk Assessment Using Accident Precursor Data and Bayesian Theory; Memorial University of Newfoundland: St. John's, NL, Canada, 2009.

39. Enrico, Z. An Introduction to the Basics of Reliability and Risk Analysis; World Scientific: Singapore, 2007.

40. OREDA. Offshore Reliability Data Handbook; OREDA: Trondheim, Norway, 2009.

41. Vose, D. Risk Analysis: A Quantitative Guide; John Wiley \& Sons: Hoboken, NJ, USA, 2008.

42. Hansen, O.R.; Gavelli, F.; Ichard, M.; Davis, S.G. Validation of FLACS against experimental data sets from the model evaluation database for LNG vapour dispersion. J. Loss Prev. Process Ind. 2010, 23, 857-877. [CrossRef]

43. Hansen, O.R.; Hinze, P.; Engel, D.; Davis, S. Using computational fluid dynamics (CFD) for blast wave predictions. J. Loss Prev. Process Ind. 2010, 23, 885-906. [CrossRef]

44. Bae, M.H.; Paik, J.K. Effects of structural congestion and surrounding obstacles on the overpressure loads in explosions: Experiment and CFD simulations. Ships Offshore Struct. 2018, 13, 165-180. [CrossRef]

45. Dasgotra, A.; Teja, G.V.; Sharma, A.; Mishra, K.B. CFD modeling of large-scale flammable cloud dispersion using FLACS. J. Loss Prev. Process Ind. 2018, 56, 531-536. [CrossRef]

46. Deng, J.; Cheng, F.; Song, Y.; Luo, Z.; Zhang, Y. Experimental and simulation studies on the influence of carbon monoxide on explosion characteristics of methane. J. Loss Prev. Process Ind. 2015, 36, 45-53. [CrossRef]

47. Wang, Q.; Sun, Y.; Li, X.; Shu, C.M.; Wang, Z.; Jiang, J.; Zhang, M.; Cheng, F. Process of Natural Gas Explosion in Linked Vessels with Three Structures Obtained Using Numerical Simulation. Processes 2020, 8, 52. [CrossRef]

48. Li, Z.; Wu, J.; Liu, M.; Li, Y.; Ma, Q. Numerical Analysis of the Characteristics of Gas Explosion Process in Natural Gas Compartment of Utility Tunnel Using FLACS. Sustainability 2020, 12, 153. [CrossRef]

49. Giannopoulos, G.; Larcher, M.; Casadei, F.; Solomos, G. Risk assessment of the fatality due to explosion in land mass transport infrastructure by fast transient dynamic analysis. J. Hazard. Mater. 2010, 173, 401-408. [CrossRef] [PubMed]

50. Assael, M.J.; Kakosimos, K.E. Fires, Explosions, and Toxic Gas. Dispersions; CRC Press: Boca Raton, FL, USA, 2010.

51. Z. NORSOK. "Z-013" Risk and Emergency Preparedness Analysis; Norwegian Technology Standards Institution: Oslo, Norway, 2001.

52. Vannak, D.; Liew, M.S.; Yew, G.Z. Time domain and frequency domain analyses of measured Metocean data for Malaysian waters. World Acad. Sci. Eng. Technol. 2013. [CrossRef]

53. DNV. Failure Frequency Guidance: Process Equipment Leak Frequency Data for Use in QRA; DNV: Oslo, Norway, 2012.

54. GexCon AS. FLACS v10. 8 User's Manual; GexCon AS: Bergen, Norway, 2017.

55. Vinnem, J.-E. Offshore Risk Assessment: Principles, Modelling and Applications of QRA Studies; Springer Science \& Business Media: Berlin, Germany, 2013.

56. Johnson, J.W.; Rasmuson, D.M. The US NRC's accident sequence precursor program: An overview and development of a Bayesian approach to estimate core damage frequency using precursor information. Reliab. Eng. Syst. Saf. 1996, 53, 205-216. [CrossRef]

57. Niazi, U.M. Grid Based Dynamic Risk Analysis Using CFD Simulation of Vapour Cloud Explosion for Offshore Facilities. Ph.D. Thesis, University Technology Petronas, Perak, Malaysia, 2020.

58. Bao, Q.; Fang, Q.; Zhang, Y.; Chen, L.; Yang, S.; Li, Z. Effects of gas concentration and venting pressure on overpressure transients during vented explosion of methane-air mixtures. Fuel 2016, 175, 40-48. [CrossRef]

59. Kim, W.K.; Mogi, T.; Dobashi, R. Fundamental study on accidental explosion behavior of hydrogen-air mixtures in an open space. Int. J. Hydrog. Energy 2013, 38, 8024-8029. [CrossRef]

60. CCPS. Guidelines for Evaluating the Characteristics of Vapour Cloud Explosions, Flash Fires and BLEVEs; CCPS: Jonesboro, GA, USA, 1994.

61. Li, D.; Zhang, Q.; Ma, Q.; Shen, S.; Chen, J.; Ren, S. Influence of built-in obstacles on unconfined vapour cloud explosion. J. Loss Prev. Process Ind. 2016, 43, 449-456. [CrossRef]

62. Zhang, S.; Zhang, Q. Influence of geometrical shapes on unconfined vapour cloud explosion. J. Loss Prev. Process Ind. 2018, 52, 29-39. [CrossRef]

(C) 2020 by the authors. Licensee MDPI, Basel, Switzerland. This article is an open access article distributed under the terms and conditions of the Creative Commons Attribution (CC BY) license (http://creativecommons.org/licenses/by/4.0/). 